
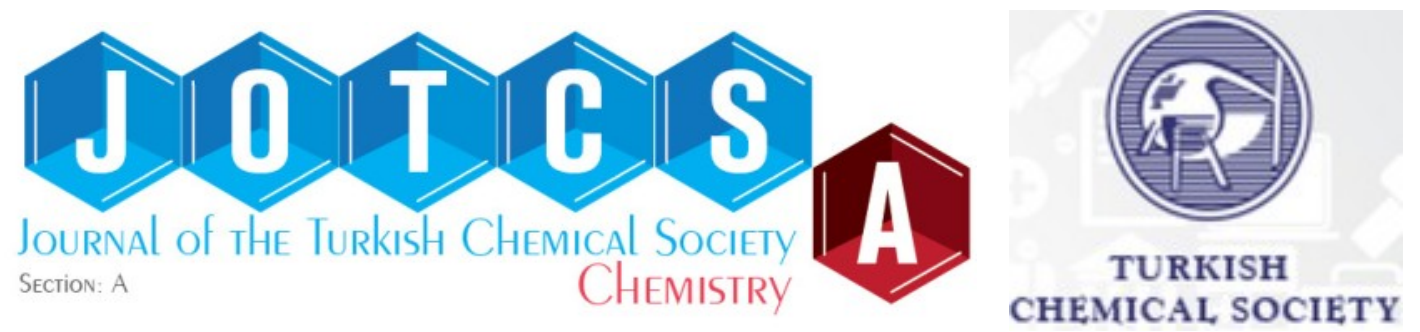

\title{
Physicochemical Analysis and Heavy Metals Remediation of Pharmaceutical Industry Effluent Using Bentonite Clay Modified by $\mathrm{H}_{2} \mathrm{SO}_{4}$ and $\mathrm{HCl}$
}

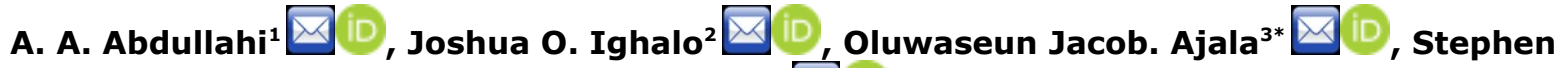 \\ Ayika $^{3}$ iD \\ ${ }^{1}$ Department of Chemistry, Faculty of Physical Sciences, University of Ilorin, P.M. B. 1515, Ilorin, \\ Nigeria. \\ 2 Department of Chemical Engineering, Faculty of Engineering and Technology, University of Ilorin, \\ P.M. B. 1515, Ilorin, Nigeria. \\ ${ }^{3}$ Department of Industrial Chemistry, Faculty of Physical Sciences, University of Ilorin, P.M. B. \\ 1515, Ilorin, Nigeria.
}

Abstract: Environmental pollution by industrial effluent has become a vital issue partly because of the detection of heavy metals in them, which need to be mitigated. Adsorbents were produced from Bentonite clay using $2 \mathrm{M} \mathrm{H}_{2} \mathrm{SO}_{4}$ and $2 \mathrm{M} \mathrm{HCl}$ as modifying agents in ratio $1: 2$ by wet impregnation method. Physicochemical properties of the pharmaceutical effluents such as $\mathrm{pH}$, temperature, turbidity, conductivity, Chemical Oxygen Demand (COD), Biological Oxygen Demand (BOD), and heavy metals were determined. High concentrations of Fe(III) and Zn(II)were observed in the effluents when compared with standards. The optimal value of $\mathrm{pH}$ for Fe(III) and $\mathrm{Zn}$ (II) was 8 , and a dose of $0.05 \mathrm{~g}$ was found to be the optimal value for all the adsorption system. The adsorption was best fit to Langmuir isotherm and the pseudo-second-order kinetic model. The results obtained in this study showed that the produced adsorbents could be used to supplement the commercial adsorbents in the specific application. Furthermore, the acid modification was helped to increase the sorption capacity of the clay to the heavy metals studied with $\mathrm{H}_{2} \mathrm{SO}_{4}$ being the better modification agent.

Keywords: Adsorption, Bentonite, Pharmaceutical Effluent, Heavy metals, Inorganic Acids

Submitted: March 15, 2020. Accepted: July 11, 2020.

Cite this: Abdullahi AA, Ighalo JO, Ajala OJ, Ayika S. Physicochemical Analysis and Heavy Metals Remediation of Pharmaceutical Industry Effluent Using Bentonite Clay Modified by $\mathrm{H}_{2} \mathrm{SO}_{4}$ and $\mathrm{HCl}$. JOTCSA. 2020; 7(3); 727-744.

DOI: https://doi.org/10.18596/jotcsa.703913.

*Corresponding author. E-mail: oluwaseun ajala81@yahoo.com, oluwaseunajala404@gmail.com. Tel: +2347039121853.

\section{INTRODUCTION}

The pollution of water by industrial effluents is a serious environmental challenge in recent times due to the increased activities of industries (such as pharmaceutical, mining, metallurgical, tannery, paint, nuclear, and batteries) $(1,2)$. Heavy metals can be considered as a group of trace elements with an atomic density greater than $4 \pm 1 \mathrm{~g} / \mathrm{cm}^{3}$ (3). These include $\mathrm{Al}, \mathrm{Ni}, \mathrm{As}$, 
$\mathrm{Co}, \mathrm{Ag}, \mathrm{Cr}, \mathrm{Mn}, \mathrm{Fe}, \mathrm{Sn}, \mathrm{Pb}, \mathrm{Cd}, \mathrm{Hg}, \mathrm{Zn}$, and $\mathrm{Cu}$, among others (4). Several characteristics of these heavy metals (i.e., high solubility, stability, and high migration activity in aqueous media) have led to their bio-magnification, causing varieties of human illness and other negative environmental impacts $(5,6)$.

A porous clay known as bentonite (with montmorillonite as its critical phase) is readily available $(7,8)$ and have been investigated by researchers as adsorbents to remove pesticides, herbicides $(8,9)$ various organic pollutants, heavy metals and a host of others $(10,11)$ from aqueous media. Bentonite is also very important and essential in many other fields such as iron ore pelletizing, drilling mud, foundry and binding, and civil engineering such as sealing and waterproofing (12).

Several recent modification techniques have been studied for bentonite clays in heavy metal adsorption (alongside the use of unmodified clays). Schütz et. al (13) modified bentonite with manganese to improve its affinity for Cd(II) uptake. Tohdee and Kaewsichan (14) utilized Bencylhexadecyldimethyl ammonium chloride for the modification of bentonite for $\mathrm{Cu}(\mathrm{II})$ and $\mathrm{Zn}$ (II) uptake via adsorption with positive results. Yan et. al (15) investigated the facile solvothermal synthesis of $\mathrm{Fe}_{3} \mathrm{O}_{4}$ /bentonite for the adsorption of $\mathrm{Pb}$ (II), $\mathrm{Cu}(\mathrm{II})$, and $\mathrm{Cd}(\mathrm{II})$. Cantuaria et. al (16) studied the use of unmodified bentonite for the adsorption of silver from aqueous media. Alduaij et. al (17) studied the use of unmodified bentonite sourced from the Saudi area for the adsorption of $\mathrm{Co}$ (II).

Acid modification is a well-established preparation and modification technique for adsorbents (1). The use of inorganic acidmodified bentonite to study $\mathrm{Zn}$ (II) and Fe(III) sorption is unreported, leaving us a viable knowledge gap to explore. Furthermore, this study is geared towards a specific environmental problem in Nigeria, which it's $\mathrm{Zn}$ (II) and $\mathrm{Fe}$ (III) pollution from industrial effluents in Ilorin city. In this research work, the inherent adsorption strength of bentonite clays for the removal of heavy metals was investigated, and several factors (contact time, adsorbent dosage, $\mathrm{pH}$, initial concentrations, and temperatures) were considered. Furthermore, isotherm, kinetics, and thermodynamics studies were conducted to gain more understanding of the adsorption process.

\section{MATERIALS AND METHOD}

\section{Collection and Preparation of Adsorbents}

The clay sample was collected from Afuze, Edo state, southern Nigeria. It was sun-dried, ground into fine powder by the use of a mortar and pestle and sieved using $2 \mu \mathrm{m}$ geometrical sized screen. It was then transferred to a beaker and oven-dried at $110{ }^{\circ} \mathrm{C}$ for $24 \mathrm{~h}$ to remove water content and volatile impurities (18). The dried clay sample was removed and cooled in a desiccator containing $\mathrm{CaCl}_{2}$ for $45-60$ min. The dried clay was labeled as unmodified clay (UMBC) while the air-dried clay (size $2 \mu \mathrm{m}$ ) was equilibrated with $2.0 \mathrm{M}$ sulfuric acid and stirred with a glass rod for 30 minutes and shaken for $1 \mathrm{~h}$ with a rotary shaker (19). The mixture was oven dried for $6 \mathrm{~h}$ at a temperature of $80{ }^{\circ} \mathrm{C}$ until a paste-like material is formed and allowed to cool. It was then washed several times using distilled water until the washed solution was of neutral $\mathrm{pH}$. The same procedure was repeated for $2.0 \mathrm{M}$ Hydrochloric acid. The two modified clays were then air-dried, sieved, and labeled as sulfuric acid modified clay (SMBC) and hydrochloric acid modified clay (HMBC), respectively (20).

\section{Determination of Physicochemical Parameters of the Industrial Effluents}

Effluent samples were analyzed to determine the pollutants/contaminants present through physicochemical analysis methods such as temperature, $\mathrm{pH}$, turbidity, color and odor, and electrical conductivity.

\section{Determination of Chemical Parameters of the Industrial Effluents Chemical Oxygen Demand (COD)}

A blank solution was prepared by pipetting a distilled water of $100 \mathrm{~mL}$ into a conical flask of $250 \mathrm{~mL}$. A $10 \mathrm{~mL}$ portion of $25 \% \mathrm{H}_{2} \mathrm{SO}_{4}$ and 20 $\mathrm{mL}$ of $0.01 \mathrm{M} \mathrm{KMnO}_{4}$ was added to the solution. Then, $10 \mathrm{~mL}$ of the water sample was measured into another $250 \mathrm{~mL}$ conical flask and diluted with $90 \mathrm{~mL}$ of distilled water. A $10 \mathrm{~mL}$ portion of $25 \% \mathrm{H}_{2} \mathrm{SO}_{4}$ and $20 \mathrm{~mL}$ of $0.01 \mathrm{M} \mathrm{KMnO}_{4}$ was added to the solution. The solutions were heated on a boiling water bath for 30 minutes. Afterward, the solution in the flasks was allowed to cool, and $10 \mathrm{~mL}$ of $10 \% \mathrm{KI}$ solution was added to each (21). The average values were taken by repeating the procedure three times. The chemical oxygen demand (COD) was calculated using Eqn. 1

$$
C O D=\frac{(A-B) \times M \times 40000}{\text { Volume }(m L) o f s a m p l e} \quad \text { Eqn. } 1
$$


Where $A$ is the titer value of the sample, $B$ is the titer value of the blank solution; $M$ is the molarity of $\mathrm{KMnO}_{4}$ and $\mathrm{V}$ is the volume of sample.

\section{Dissolved Oxygen (DO)}

Dissolved oxygen is the determination of the amount of oxygen present in a sample of water or wastewater at the time of collection. Winkler's titration was used for measurement (22). The average values were taken by repeating the procedure three times. Eqn. 2 was the expression used.

$$
D O(m g / L)=\frac{1600 \times M \times V}{V 2 / V 1(V 1-V 2)}
$$

\section{Biochemical Oxygen Demand (BOD)}

The effluent samples were divided into two. The DO level (ppm) of the first portion was measured immediately using the method described in the dissolved oxygen test and Recorded. The second portion of the effluent sample was placed in complete darkness by wrapping the effluent sample bottles with aluminum foil at room temperature for 3 days (ASTM, 1982). The average values were taken by repeating the procedure three times.

\section{Acidity Level}

Determination of acidity level was done usually by titration. An effluent's portion of the sample was pipetted into a conical flask. Phenolphthalein indicator was added in two drops, and the solution was titrated against a standardized $0.01 \mathrm{M}$ sodium hydroxide solution to a pink end-point (23). The average values were taken by repeating the procedure three times. Acidity was calculated using Eqn. 3

$$
\operatorname{Acidity}(m g / L)=\frac{V \times M \times 100,000}{m L o f \text { sample used }} \quad \text { Eqn. } \mathbf{3}
$$

\section{Alkalinity Level \\ A sample of the effluent's portion was pipetted into a conical flask. Methyl red indicator was added in two drops, and the solution was titrated against a standardized $0.01 \mathrm{M} \mathrm{HCl}$ solution to a pink end-point (23). The average values were taken by repeating the procedure three times. Alkalinity was calculated using Eqn. 4}

$$
\operatorname{Alkalinity}(m g / L)=\frac{V \times M \times 100,000}{m L o f \text { sample used }} \quad \text { Eqn. } 4
$$

\section{Total Hardness}

An effluent of $25 \mathrm{~mL}$ was pipetted into a different conical flask. To this, $3 \mathrm{~mL}$ of ammonium chloride in a concentrated ammoniacal buffer $\left(\mathrm{NH}_{4} \mathrm{Cl} /\right.$ conc. $\left.\mathrm{NH}_{3}\right)$ and Eriochrome Black $\mathrm{T}$ indicator was added in two drops. It was titrated against $0.01 \mathrm{M}$ EDTA solution until there is a color change from violet to blue. The average values were taken by repeating the procedure three times (21). Total Hardness was calculated using Eqn. 5

Hardness in $\mathrm{mg} / \mathrm{LCaCO}_{3}=\frac{V \times M \times 100,000}{m L \text { ofsample used }}$ Eqn. 5

\section{Heavy Metals}

Iron and zinc were determined using Atomic Absorption Spectrophotometer (model AA6800SHIMADZU) according to APHA (24).

\section{Batch Adsorption Experiment Effect of Initial Metal Concentration}

Effect of initial metal ion concentration on percentage removal of metal ions was investigated by varying the concentration of the metal ions in the range of 5 to $50 \mathrm{mg} / \mathrm{L}$ while keeping other factors constant (i.e., time - 180 minutes, dose $-0.05 \mathrm{~g}, \mathrm{pH}-6$, temperature $25^{\circ}$ C). A $50 \mathrm{~mL}$ portion of separate concentrations of metal ions (i.e., 20, 40, 60, 80 , and $100 \mathrm{mg} / \mathrm{L}$ ) was introduced into $0.05 \mathrm{~g}$ of clay adsorbent. The mixture was shaken vigorously and continuously on a mechanical shaker for 150 minutes and then filtered. Atomic Absorption Spectrophotometer determined the final concentration of each filtrate solution. The amount of metal ions adsorbed $\mathrm{q}_{\mathrm{e}}$, and percentage removal of metal ions was determined.

\section{Effect of $\mathrm{pH}$}

Effect of $\mathrm{pH}$ on percentage removal of metal ions was investigated by varying the $\mathrm{pH}$ from $\mathrm{pH} 2$ to $\mathrm{pH} 10$ with the use of $0.1 \mathrm{M} \mathrm{NaOH}$ or $0.1 \mathrm{M} \mathrm{HNO}_{3}$ while keeping other factors constant (i.e., time - 180 minutes, dose - $0.05 \mathrm{~g}$, temperature $-25^{\circ} \mathrm{C}$, particle size $-2 \mu \mathrm{m}$ ). 0.05 $\mathrm{g}$ of the adsorbent was weighed into 5 beakers, and $20 \mathrm{~mL}$ of the industrial effluents were introduced into the beakers. The mixture was shaken vigorously and continuously on a mechanical shaker for 150 minutes and then filtered. Atomic Absorption Spectrophotometer will determine the final concentration of each filtrate solution. The amount of metal ions adsorbed $\mathrm{q}_{\mathrm{e}}$ and percentage removal of metal ions was determined. 


\section{Effect of Contact Time}

The effect of contact time on the removal of heavy metals from the industrial effluents was investigated by keeping other factors constant (i.e., dose - $0.05 \mathrm{~g}, \mathrm{pH}$ - 6, temperature $25^{\circ} \mathrm{C}$, particle size - $\left.2 \mu \mathrm{m}\right) .1 .0 \mathrm{~g}$ of the adsorbent was weighed into 6 beakers, and 20 $\mathrm{mL}$ of industrial effluents were introduced to each beaker. The mixture was shaken vigorously and continuously on a mechanical shaker for a varying period ranging from 30 150 minutes and then filtered. Atomic Absorption Spectrophotometer determined the final concentration of each filtrate solution. The amount of metal ions adsorbed $\mathrm{q}_{\mathrm{e}}$, and percentage removal of metal ions was determined.

\section{Effect of Temperature}

The effect of temperature on percentage removal of metal ions was investigated by varying the temperature of the mechanical shaker in the range of 15 to $40^{\circ} \mathrm{C}$ while keeping other factors constant (i.e., time - 180 minutes, $\mathrm{pH}-6$, dose $-0.05 \mathrm{~g}$, particle size -2 $\mu \mathrm{m}) .20 \mathrm{~mL}$ portions of the industrial effluent were introduced into each beaker containing 0.05 grams of the adsorbent. The mixture was shaken vigorously and continuously on a mechanical shaker for 150 minutes and then filtered at the specified temperature. Atomic Absorption Spectrophotometer determined the final concentration of each filtrate solution. The amount of the metal ions adsorbed $\mathrm{q}_{\mathrm{e}}$, and percentage removal of metal ions will be determined.

\section{Effect of Adsorbent Dose}

Effect of adsorbent dose on percentage removal of metal ions was investigated by varying adsorbent dose in the range of 0.05 to $2.5 \mathrm{~g}$ while keeping other factors constant (i.e., time - 180 minutes, $\mathrm{pH}-6$, temperature $-25^{\circ} \mathrm{C}$, particle size - $2 \mu \mathrm{m}$ ). A separate masses of the adsorbents (i.e. $0.05,1.0,1.5,2.0,2.5 \mathrm{~g}$ ) were weighed into 5 beakers and $20 \mathrm{~mL}$ of the industrial effluent was introduced into each beaker. The mixture was shaken vigorously and continuously on mechanical shaker for 150 minutes and then filtered. The final concentration of filtrate solutions was then determined by atomic absorption spectrophotometer. The amount of metal ions adsorbed $\mathrm{q}_{\mathrm{e}}$ and percentage removal of metal ions was determined.

\section{RESULTS AND DISCUSSION}

\section{Physicochemical Parameters of Pharmaceutical Effluents}

Pharmaceutical effluents were sourced from Ilorin, Nigeria. The results of the effluent obtained were compared with the standard values of the Federal Environmental Protection Agency (FEPA) for industrial effluents, United States - Environmental Protection Agency (USEPA). National recommended water quality criteria-correction; World Health Organization (WHO).Guidelines for drinking water recommendations. Table 1 contains the physicochemical properties of various water samples. The concentrations of heavy metals in the effluents are in the following order Fe $>\mathrm{Zn}$ $>\mathrm{Cu}>\mathrm{Mn}>\mathrm{Pb}>\mathrm{Cr}$. Nickel (Ni) and cadmium (Cd) were not detected.

Table 1: Physicochemical properties of various water samples.

\begin{tabular}{|c|c|c|c|c|}
\hline Properties & Effluent & WHO $^{a}$ & FEPA $^{b}$ & USEPA \\
\hline $\mathrm{pH}$ & 6.09 & $6-9.5$ & $6.0-9.0$ & $6.0-8.5$ \\
\hline Temperature & 33.0 & & $40^{\circ} \mathrm{C}$ & \\
\hline Color & Yellow & Colorless & NS & Colorless \\
\hline Conductivity & 451 & NS & NS & NS \\
\hline Turbidity & 33.0 & NS & NS & NS \\
\hline COD & 77.6 & NS & NS & NS \\
\hline BOD & 43 & NS & 50 & NS \\
\hline TSS & 71 & NS & 30 & NS \\
\hline TDS & 248 & $<1200$ & 2000 & 500 \\
\hline Cadmium & ND & 0.003 & $<1$ & 0.002 \\
\hline Chromium & 0.001 & 0.05 & 0.015 & 0.05 \\
\hline Nickel & ND & 0.02 & $<1$ & 0.005 \\
\hline Iron & 88.52 & NS & 20 & 0.3 \\
\hline Lead & 0.002 & 0.01 & $<1$ & 0.003 \\
\hline Zinc & 3.276 & 0.01 & $<1$ & 0.12 \\
\hline Copper & 0.762 & 1.2 & 1.3 & 0.009 \\
\hline Manganese & 0.701 & NS & 5 & 0.05 \\
\hline
\end{tabular}

All values are in $\mathrm{mg} / \mathrm{L}$ except conductivity $(\%), \mathrm{pH}$, and turbidity have no unit; NS: Not stated. 
Thus, the highest genotoxic risk in this study will be primarily accounted for by the higher concentrations of $\mathrm{Fe}$ (III) and $\mathrm{Zn}$ (II) in which are above the permissible level of WHO, FEPA, and USEPA.

\section{Adsorption Parameters}

\section{Effect of Initial Concentration}

Initial concentrations were considered for the adsorption studies in other to determine the equilibrium concentration of adsorbate, which was used to study other parameters. The results obtained for this study are shown in Figure 1a-for Fe(III) and Zn(II), respectively, and varying the initial concentrations from 20 $\mathrm{mg} / \mathrm{L}$ to $100 \mathrm{mg} / \mathrm{L}$. The notifications for the three adsorbents are as follows; unmodified bentonite clay (UMBC), $\mathrm{H}_{2} \mathrm{SO}_{4}$ modified bentonite clay (SMBC), and $\mathrm{HCl}$ Modified Bentonite clay (HMBC). In Figures 1a-b, it was observed that the Fe(III) and $\mathrm{Zn}$ (II) adsorption capacity increases with increasing initial concentration and their capacities were achieved at $15.01 \mathrm{mg} / \mathrm{g}, 8.29 \mathrm{mg} / \mathrm{g}$ and $8.29 \mathrm{mg} /$ $\mathrm{g}$ for UMBC, SMBC and HMBC with Fe(III) respectively while $14.87 \mathrm{mg} / \mathrm{g}, 7.51 \mathrm{mg} / \mathrm{g}$, and $7.98 \mathrm{mg} / \mathrm{g}$ are for UMBC, SMBC and HMBC with $\mathrm{Zn}$ (II) respectively. The increase in adsorption capacity with initial concentration is because the concentration provides a critical mass transfer driving force for the adsorption process (25).

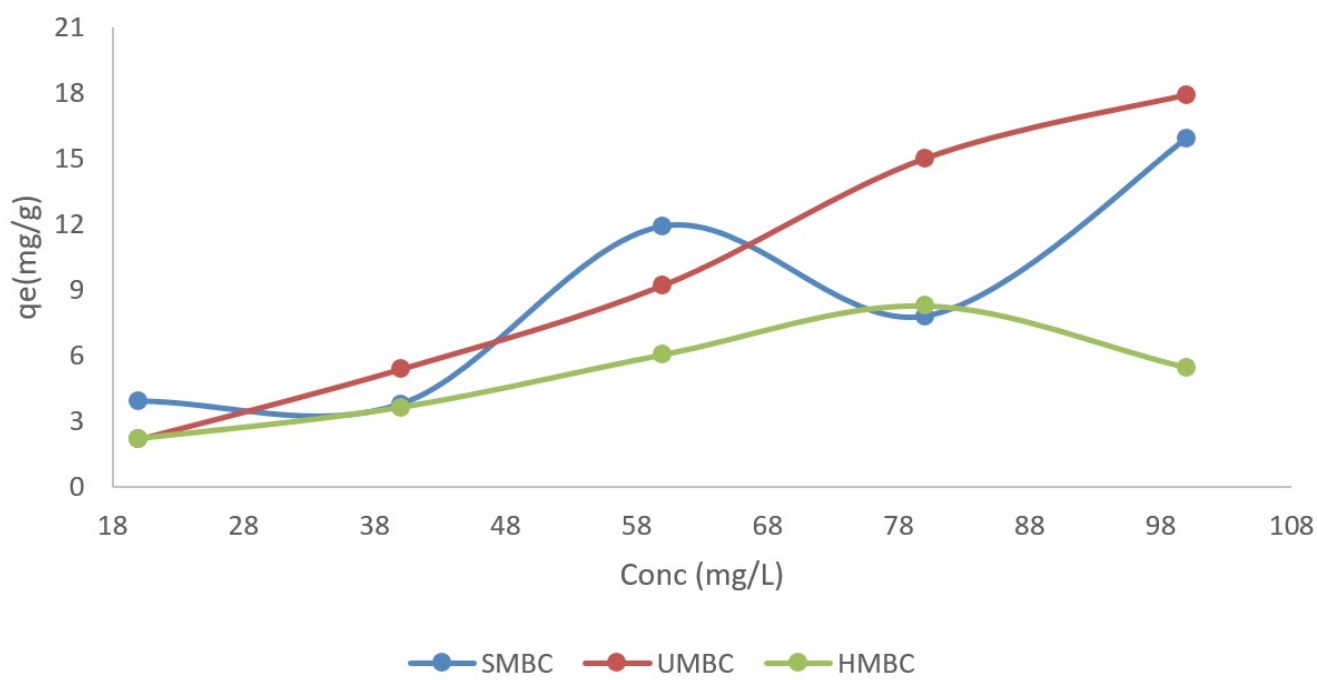

Figure 1a: Profile diagram of initial concentration on the amount of Fe(III) adsorbed using UMBC, SMBC, and HMBC.

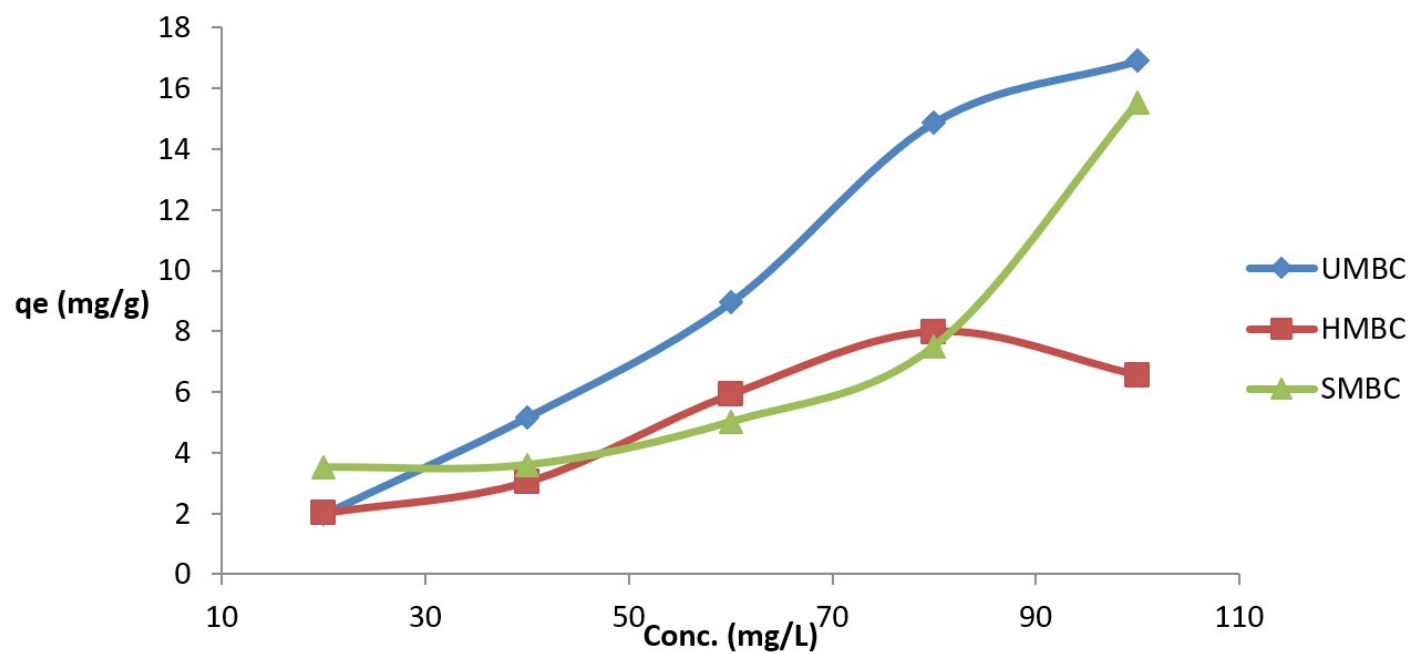

Figure 1b: Profile diagram of initial concentration on amount of $\mathrm{Zn}(\mathrm{II})$ adsorbed using UMBC, SMBC, and HMBC. 


\section{Effects of Contact Time}

The pollutants' contact time with different clay adsorbents is valuable in the adsorption process due to its great deal of influence on the adsorption capacity (26). The results obtained as shown in Figures 1c-d investigate the adsorption capacity of $\mathrm{Fe}$ (III) and $\mathrm{Zn}$ (II) respectively with $\mathrm{UMBC}, \mathrm{SMBC}$, and $\mathrm{HMBC}$ using contact time varied from $30 \mathrm{~min}$ to $150 \mathrm{~min}$ at $\mathrm{pH}$ of 6 , adsorbent dose of $0.05 \mathrm{~g}$, the temperature of $303 \mathrm{~K}$, volume of $25 \mathrm{~mL}$ and concentration of $88.52 \mathrm{mg} / \mathrm{L}$ and $3.26 \mathrm{mg} / \mathrm{L}$ for $\mathrm{Fe}(\mathrm{III})$ and $\mathrm{Zn}$ (II) respectively from the effluent. It was noticed that as the contact time was increasing, the uptake capacity is also increased until equilibrium was achieved at $13.145 \mathrm{mg} / \mathrm{g}, 16.37 \mathrm{mg} / \mathrm{g}$ and $17.4624 \mathrm{mg} / \mathrm{g}$ for UMBC, SMBC and HMBC with Fe(III) respectively and $0.555 \mathrm{mg} / \mathrm{g}, 0.461 \mathrm{mg} / \mathrm{g}$ and $0.460 \mathrm{mg} / \mathrm{g}$ for UMBC, SMBC and HMBC with $\mathrm{Zn}$ (II) respectively. The more significant contact times favors the adsorption process because it allows for more adsorbate molecules to overcome the mass transfer barrier (boundary layer effect) at the solid-liquid interphase.

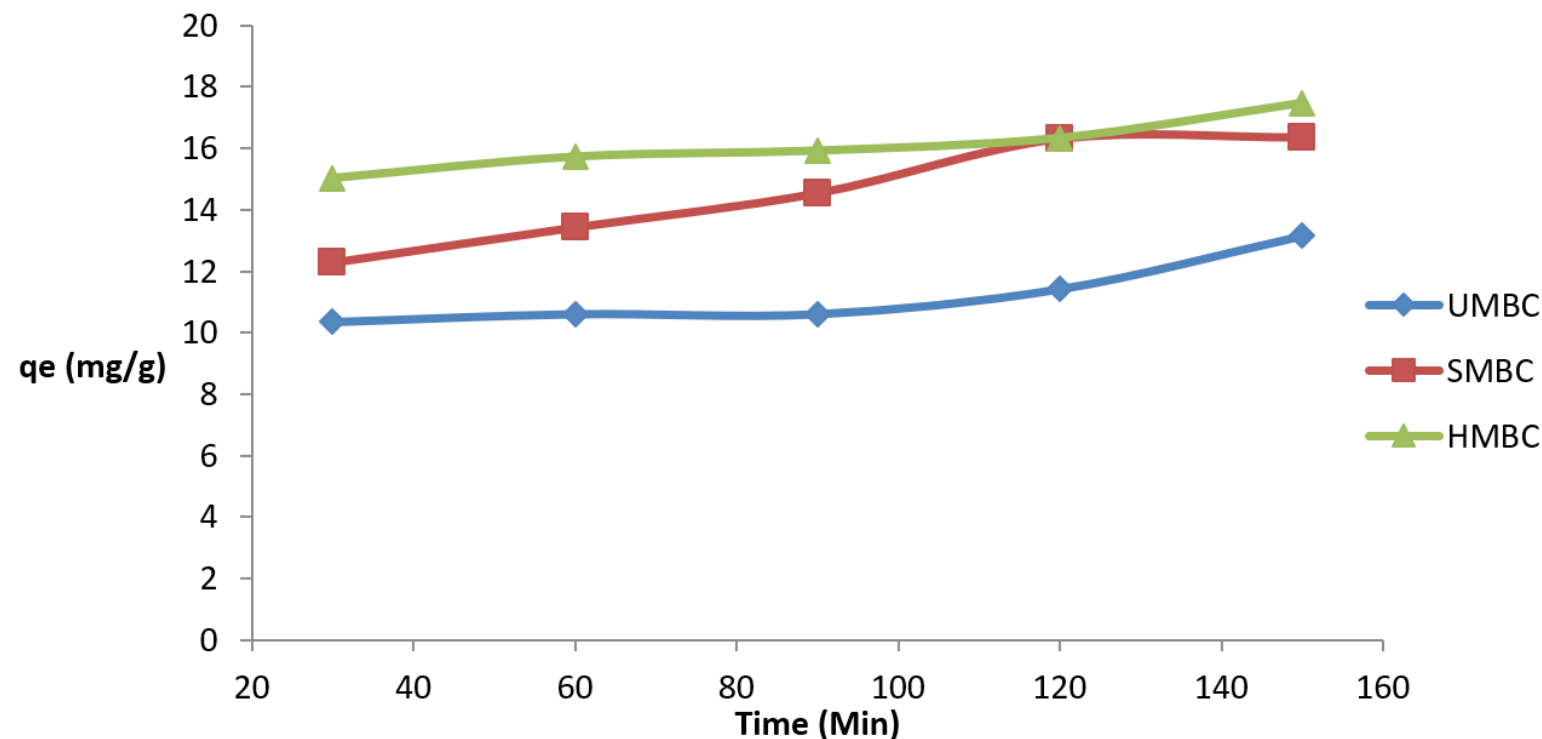

Figure 1C: Profile diagram of contact time on amount of $\mathrm{Fe}(\mathrm{III})$ adsorbed using UMBC, SMBC, and HMBC.

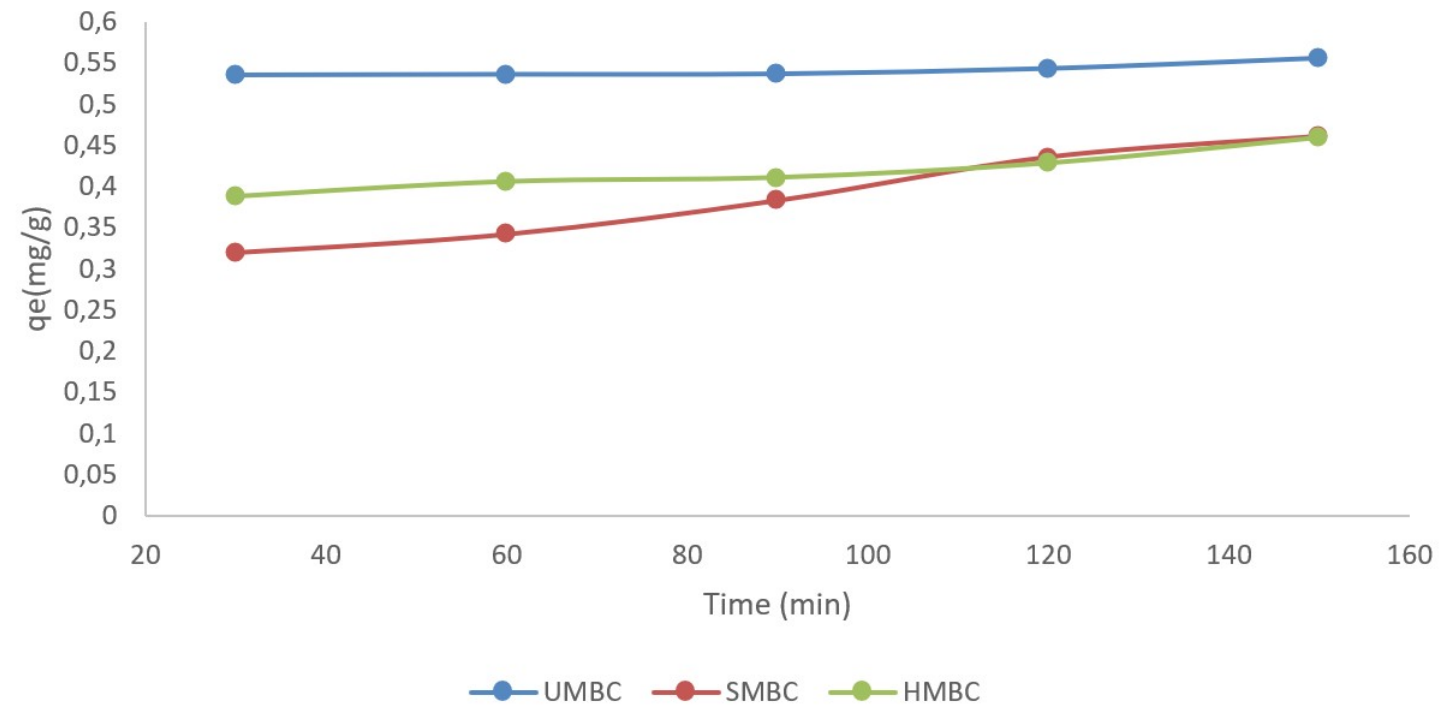

Figure 1d: Profile diagram of contact time on the amount of $\mathrm{Zn}(\mathrm{II})$ adsorbed using UMBC, SMBC, and $\mathrm{HMBC}$. 


\section{Effects of Adsorbent Dose}

The effect of adsorbent dose on the various adsorption systems was studied and was shown in the Figures 1e-f for UMBC, SMBC, and $\mathrm{HMBC}$ on $\mathrm{Fe}(\mathrm{III})$ and $\mathrm{Zn}(\mathrm{II})$ respectively. The parameters utilized for the adsorption process were contact time of $180 \mathrm{~min}$, the volume of the adsorbate in $25 \mathrm{~mL}, \mathrm{pH}$ at 6 , the temperature at $303 \mathrm{~K}$, and concentrations of $88.52 \mathrm{mg} / \mathrm{L}$ for $\mathrm{Fe}$ (III) and $3.276 \mathrm{mg} / \mathrm{L}$ for $\mathrm{Zn}$ (II). It was observed in Figure 1e that as the adsorbent dose was increased, the uptake capacity decreased and their maximum uptake was observed at $0.05 \mathrm{~g}$ mass of adsorbents in all the systems with the corresponding values of $24.145 \mathrm{mg} / \mathrm{g}, 19.78 \mathrm{mg} / \mathrm{g}$, and $44.46 \mathrm{mg} / \mathrm{g}$ for
$\mathrm{UMBC} / / \mathrm{Fe}$, $\mathrm{SMBC} / / \mathrm{Fe}$, and $\mathrm{HMBC} / / \mathrm{Fe}$ systems respectively (27). Also in Figure 1f, it was observed that the adsorbent dose increase with a decrease in the uptake capacity. Maximum uptake was observed at $0.05 \mathrm{~g}$ mass of adsorbents in all the systems with the corresponding values of $0.933 \mathrm{mg} / \mathrm{g}, 0.9625$ $\mathrm{mg} / \mathrm{g}, 0.999 \mathrm{mg} / \mathrm{g}, 1.025 \mathrm{mg} / \mathrm{g}, 3.465 \mathrm{mg} / \mathrm{g}$ and $3.546 \mathrm{mg} / \mathrm{g}$ for $\mathrm{UMBC} / / \mathrm{Fe}$, UMKC//Zn, $\mathrm{SMBC} / / \mathrm{Fe}$, SMKC//Zn, $\mathrm{HMBC} / / \mathrm{Fe}$, and $\mathrm{HMKC} / / \mathrm{Zn}$ system respectively. The higher uptake at a more massive adsorbent dose is due to greater availability of active sites in solution onto which the adsorbate can be adsorbed.

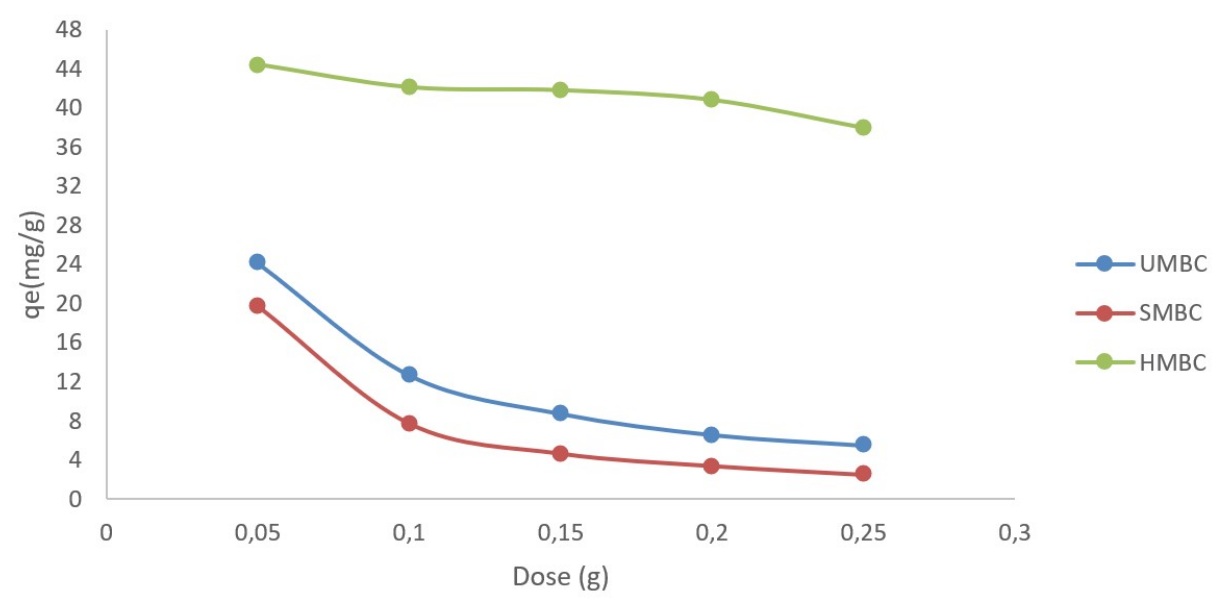

Figure 1e: Profile diagram of dose on amount of Fe(III) adsorbed using UMBC SMBC and HMBC.

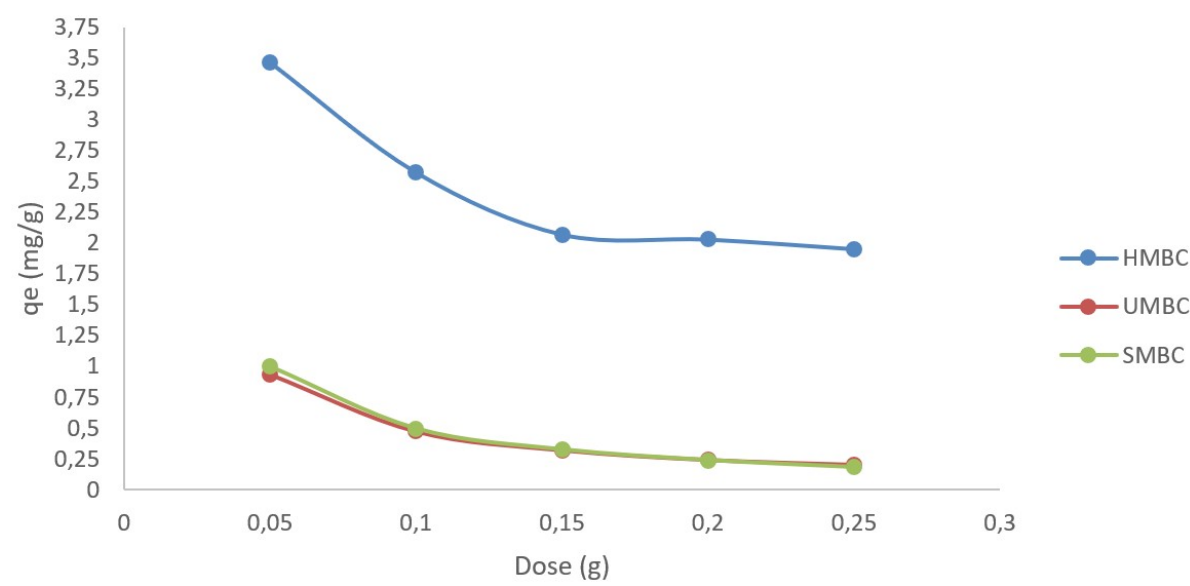

Figure 1f: Profile diagram of dose on amount of $\mathrm{Zn}(\mathrm{II})$ adsorbed using HMBC, UMBC, and SMBC

\section{Effect of $\mathrm{pH}$}

The effect of the $\mathrm{pH}$ is an important parameter controlling the adsorption process. It determines the influence of the adsorption capacity on the surface properties of the adsorbents and ionic forms of the metal ions in solutions (28). The $\mathrm{pH}$ affects the solution chemistry of the pollutant, the activity of the functional groups in the adsorbent, and the competition of ions for binding sites (1). $\mathrm{pH}$ affects the charges of the adsorbate and adsorbent in solution and hence the way they interact with each other. In this study, different 
$\mathrm{pH}$ levels ranging between 3.0 to 10.0 were considered at adsorbents dosage of $0.05 \mathrm{~g}$, Temperature: $303 \mathrm{~K}$, and concentration of 88.52 $\mathrm{mg} / \mathrm{L}$ for $\mathrm{Fe}$ (III) and $3.276 \mathrm{mg} / \mathrm{L}$ for $\mathrm{Zn}$ (II). The $\mathrm{pH}$ profile diagrams for UMBC, SMBC, and HMBC of $\mathrm{Fe}$ (III) and $\mathrm{Zn}$ (II) are shown in Figures 1g-h, respectively. In the $\mathrm{Fe}$ (III) system, it was noticed that uptake capacity was lowest at $\mathrm{pH}$ value of 3.0 with $15.935 \mathrm{mg} / \mathrm{g}$,
$11.665 \mathrm{mg} / \mathrm{g}$, and $13.0625 \mathrm{mg} / \mathrm{g}$ for UMBC, SMBC, and HMBC respectively (19). Uptake capacity, however, increased as $\mathrm{pH}$ was increased from $\mathrm{pH} 3-\mathrm{pH} 8$ (UMBC//Fe, SMBC// $\mathrm{Fe}$, and $\mathrm{HMBC} / / \mathrm{Fe}$ ), and after $\mathrm{pH} 8$, it starts to decrease. While in the case of $\mathrm{Zn}(\mathrm{II})$, the maximum uptake capacity was obtained at $\mathrm{pH} 7$ (UMBC//Zn, SMBC//Zn, and HMBC//Zn).

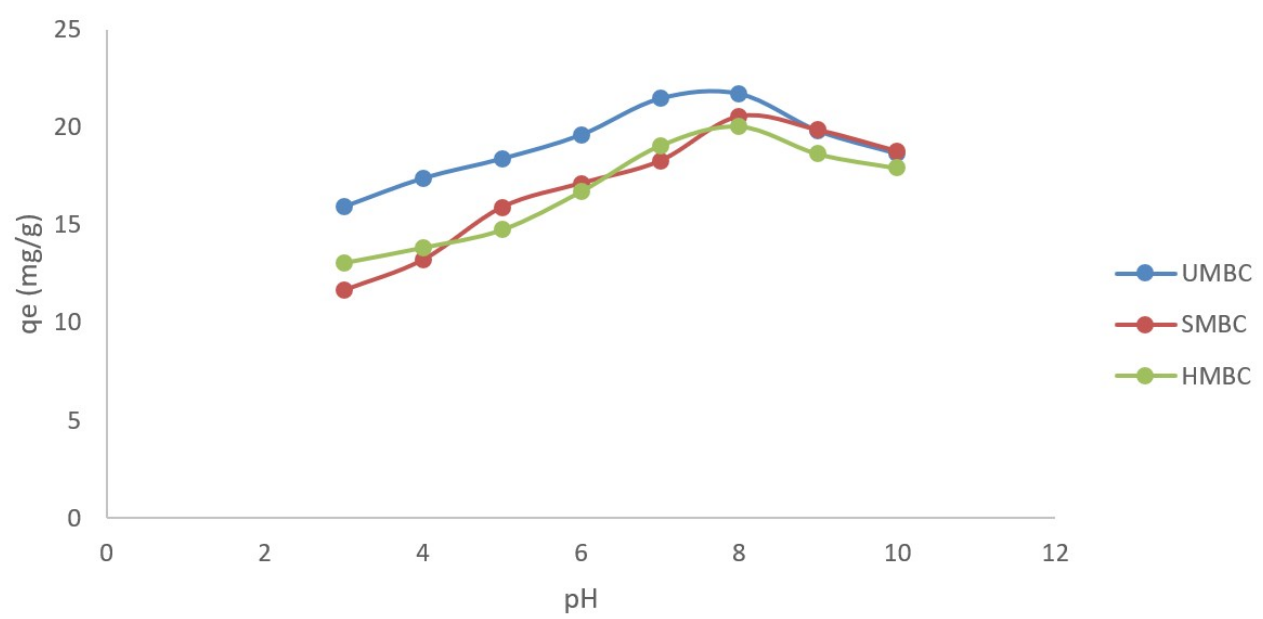

Figure 1g: Profile diagram of $\mathrm{pH}$ on the amount of Fe(III) adsorbed using UMBC SMBC and HMBC.

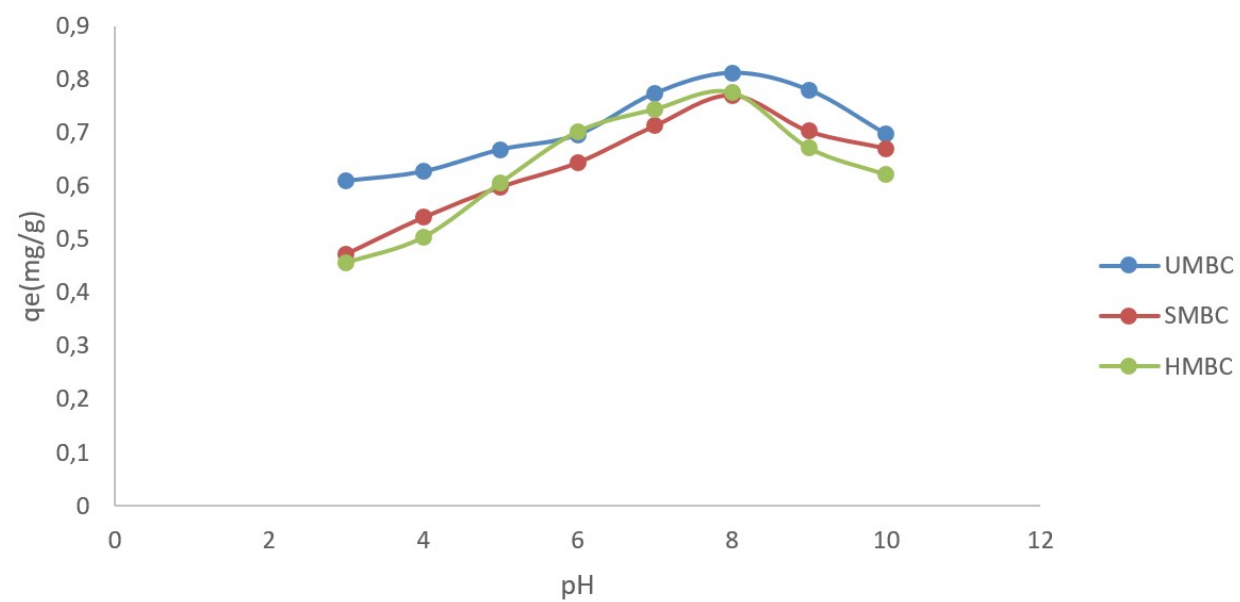

Figure 1h: Profile diagram pH on amount of $\mathrm{Zn}(\mathrm{II})$ adsorbed using UMBC, SMBC and SMBC.

\section{Effect of Temperature}

The effect of temperature on the adsorption of the $\mathrm{Fe}$ (III) and $\mathrm{Zn}$ (II) was studied using UMBC, SMBC, and HMBC. The temperature profile diagrams for the UMBC, SMBC, HMBC on $\mathrm{Fe}(\mathrm{III})$, and $\mathrm{Zn}$ (II) adsorption system are shown in Figures $\mathbf{1} \mathbf{i}-\mathbf{j}$, respectively. This work was studied at different temperatures ranging from $35^{\circ} \mathrm{C}$ to $45^{\circ} \mathrm{C}$ at adsorbents dosage of 0.05 $\mathrm{g}$, time $180 \mathrm{~min}, 25 \mathrm{~mL}$ volume, the temperature is $303 \mathrm{~K}$, at $\mathrm{pH} 6$ and concentration of $88.52 \mathrm{mg} / \mathrm{L}$ for $\mathrm{Fe}$ (III) and $3.276 \mathrm{mg} / \mathrm{L}$ for
$\mathrm{Zn}(\mathrm{II})$. All the sorption systems were observed to have a similar trend; as the temperature is increased, adsorbents' uptake capacity decreases. Generally, it is evidenced that the uptake capacity decreased with an increase in temperature. These observations suggest that process of adsorption in all the systems might be exothermic, and an increase in temperature could deteriorate the matrix structure of the adsorbents. The thermodynamics study confirmed this. 


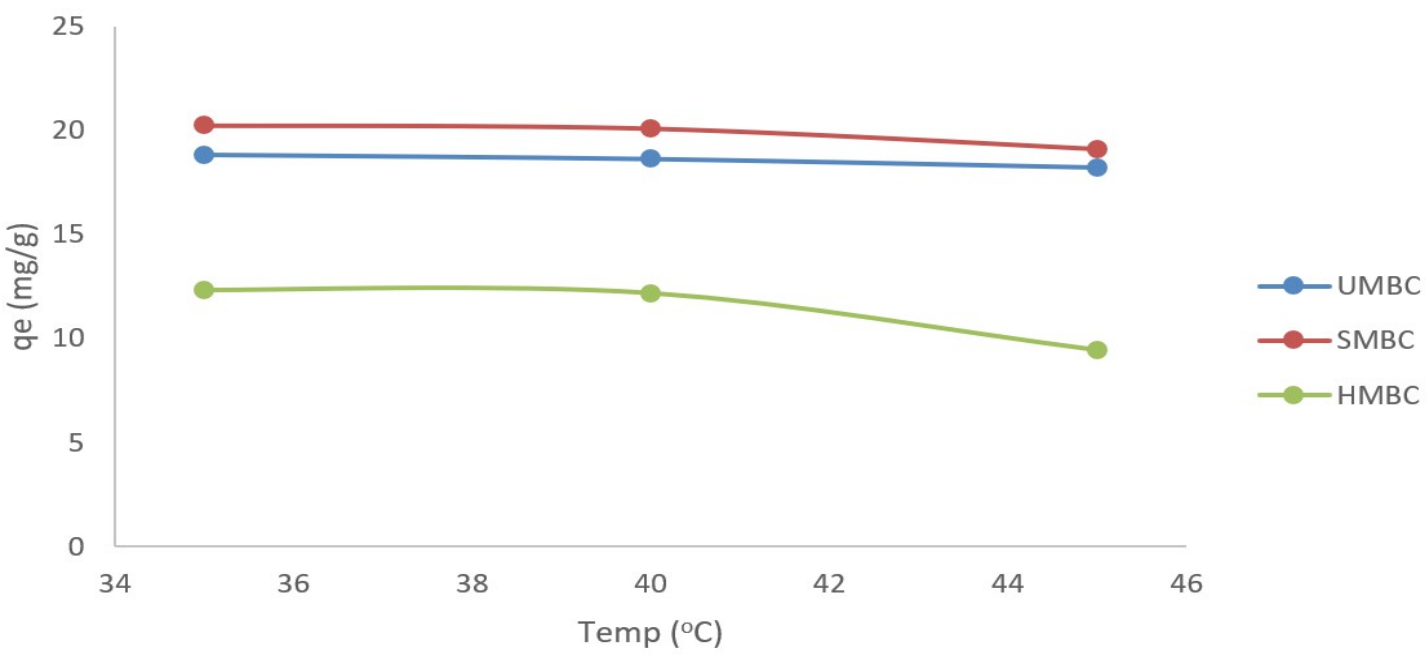

Figure 1i: Profile diagram of Temperature on the amount of $\mathrm{Fe}(\mathrm{III})$ adsorbed using HMBC, UMBC, and SMBC.

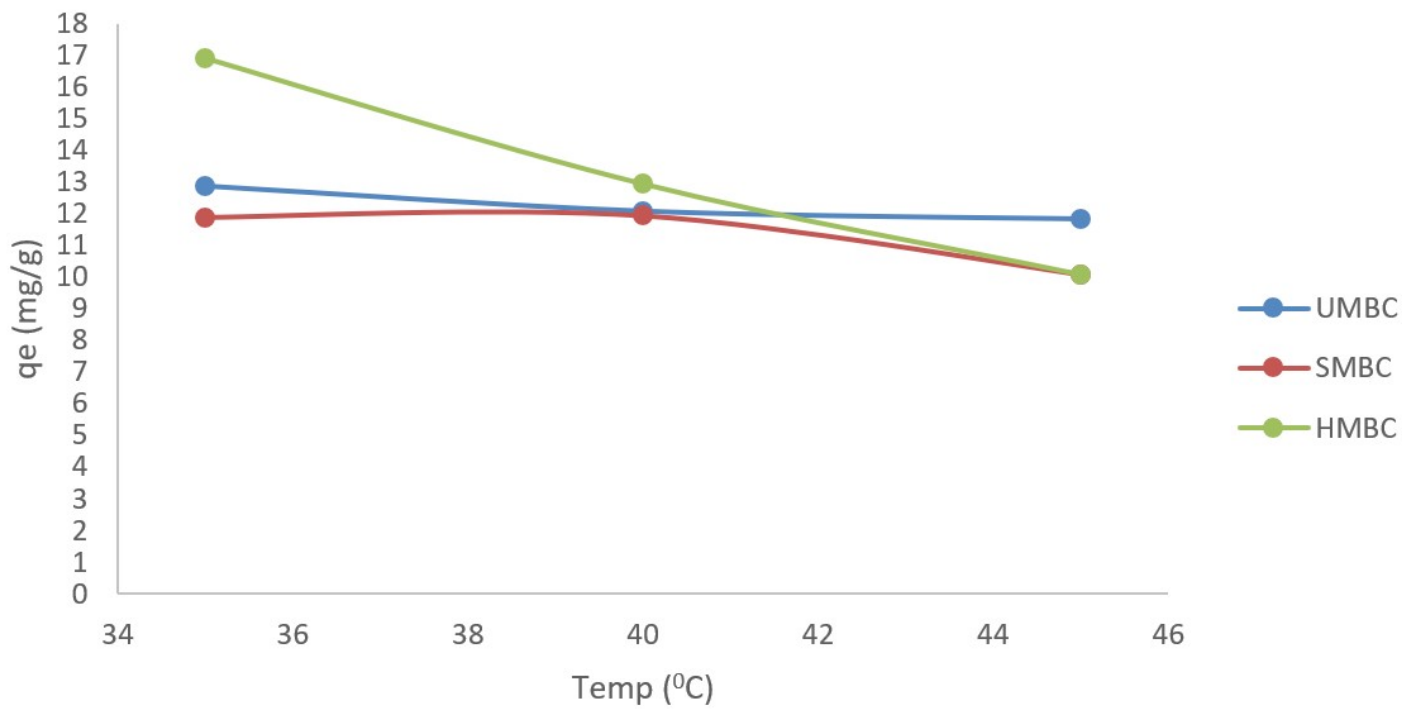

Figure 1j: Profile diagram of Temperature on amount of $\mathrm{Zn}(\mathrm{II})$ adsorbed using $\mathrm{HMBC}$, UMBC, and SMBC.

\section{Adsorption Isotherm Studies}

The equilibrium adsorption data obtained in this study were fitted with two isotherms-namely, Langmuir isotherm and Freundlich isotherm, and which all explained the different degrees of success.

\section{Langmuir Asorption Isotherm}

The data obtained from Figures 2a-b was used on this isotherm, and the parameters obtained from these plots are summarized in Tables 23. The parameters are $\mathrm{R}^{2}$ (Correlation coefficient), $\mathrm{Q}_{\max }$ (maximum adsorption capacity), and $R_{L}$ (dimensionless separation factor). It was noticed that the correlation coefficient for all the three systems is 0.933 for
UMBC, 0.997 for SMBC, and 0.915 for HMBC. It was noted that HMBC has an adsorption capacity value of $13.00 \mathrm{mg} / \mathrm{g}$, which is more than that of the UMBC $(4.2 \mathrm{mg} / \mathrm{g})$ and SMBC (2.8 $\mathrm{mg} / \mathrm{g}$ ). Also, $\mathrm{R}_{\mathrm{L}}$ value (dimensionless separation factor) is explained as a valuable feature in this process, and it ranges from 0 to 1 (19). As shown in Table 2, it affirms that the removal of heavy metals molecules is appreciated onto all the adsorbents. Furthermore, it can be observed that acid modification helped to increase the sorption capacity of the clay to the heavy metals studied. 
Table 2: Langmuir adsorption parameter for various sorption systems of Fe(III).

\begin{tabular}{cllll}
\hline SYSTEM (Fe) & $\mathrm{Q}_{\max }(\mathrm{mg} / \mathrm{g})$ & $\mathrm{K}_{\mathrm{L}}(\mathrm{l} / \mathrm{mg})$ & $\mathrm{R}_{\mathrm{L}}$ & $\mathrm{R}^{2}$ \\
\hline SMBC & 2.8 & 0.09 & 0.009 & 0.987 \\
UMBC & 4.2 & 0.03 & 0.009 & 0.933 \\
HMBC & 13.0 & 0.02 & 0.009 & 0.915 \\
\hline
\end{tabular}

$\mathrm{Q}_{\max }=$ Maximum Adsorption capacity, $\mathrm{K}_{\mathrm{L}}=$ Rate of Adsorption, $\mathrm{R}_{\mathrm{L}}=$ Separation factor

Table 3: Langmuir adsorption parameter for various sorption systems of $\mathrm{Zn}$ (II).

\begin{tabular}{ccccc}
\hline SYSTEM $(\mathrm{Zn})$ & $\mathrm{Q}_{\max }(\mathrm{mg} / \mathrm{g})$ & $\mathrm{K}_{\mathrm{L}}(\mathrm{l} / \mathrm{mg})$ & $\mathrm{R}_{\mathrm{L}}$ & $\mathrm{R}^{2}$ \\
\hline UMBC & 2.9 & 0.03 & 0.0097 & 0.937 \\
SMBC & 35.5 & 0.02 & 0.0098 & 0.922 \\
HMBC & 14.1 & 0.01 & 0.0099 & 0.921 \\
\hline
\end{tabular}

$\mathrm{Q}_{\max }=$ Maximum Adsorption capacity, $\mathrm{K}_{\mathrm{L}}=$ Rate of Adsorption, $\mathrm{R}_{\mathrm{L}}=$ Separation factor

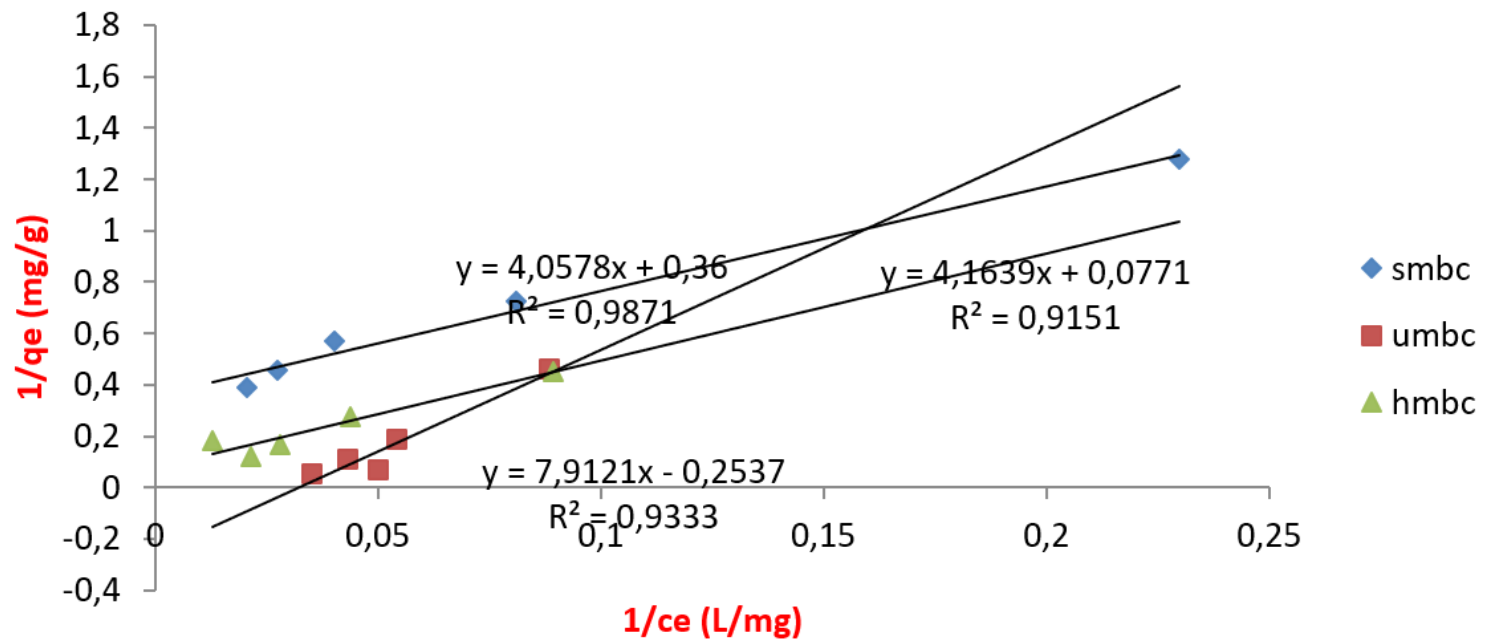

Figure 2a: Langmuir plot for $\mathrm{UMBC} / / \mathrm{Fe}, \mathrm{HMBC} / / \mathrm{Fe}$, and $\mathrm{SMBC} / / \mathrm{Fe}$.

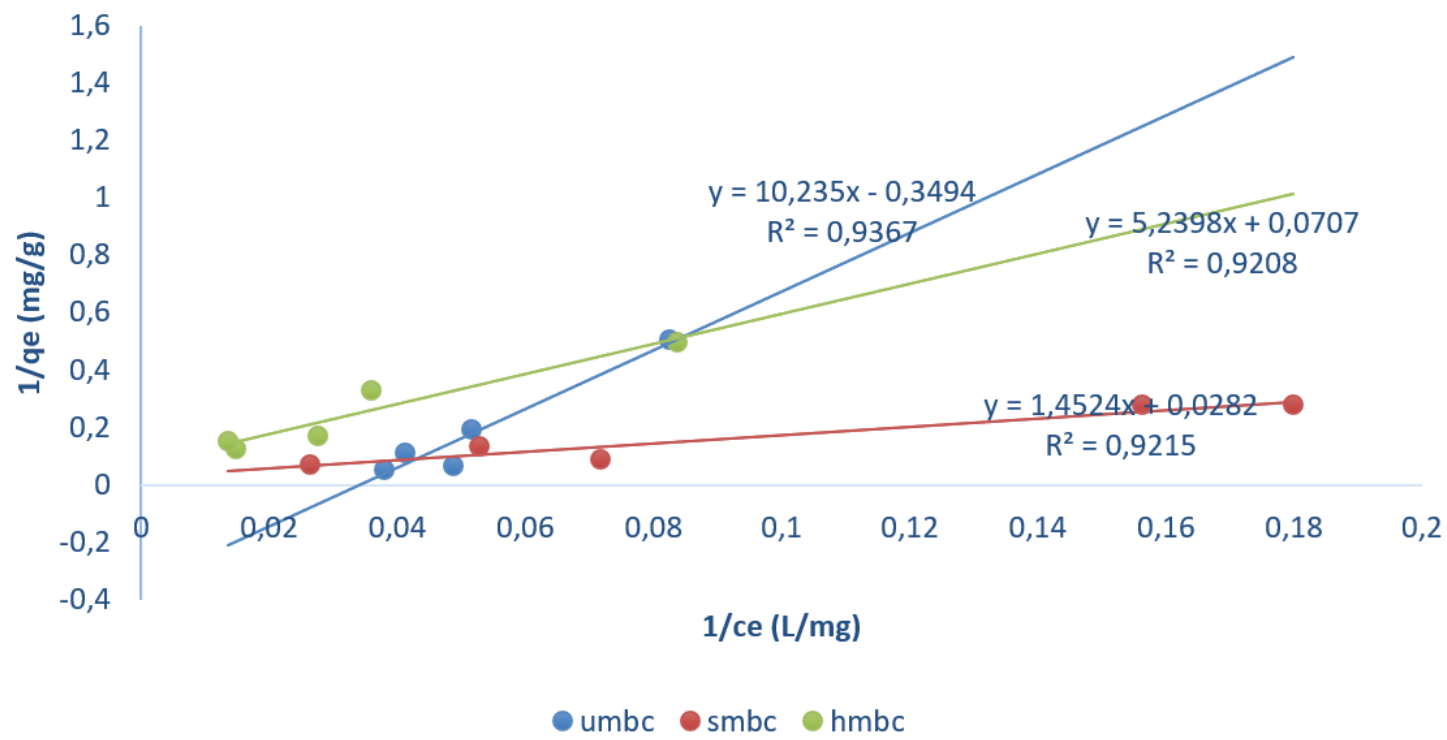

Figure 2b: Langmuir plot for UMBC//Zn, $\mathrm{HMBC} / / \mathrm{Zn}$, and $\mathrm{SMBC} / / \mathrm{Zn}$

Freundlich Adsorption Isotherm

The Freundlich plots for the various systems studied are given in Figures $\mathbf{2 c - d}$, and the parameter obtained from these plots are summarized in Tables 4-5. The value of $1 / n<$ 1 obtained in most of the adsorption system 
studied indicated favorable adsorption while in the case of UMBC in which the value of $1 / n$ is greater than $1(1 / n>1)$, it indicates the unfavorable adsorption while the value of $n$ within the range of 1 - 10 represent good adsorptions (29).

Table 4: Freundlich adsorption parameter for various adsorption systems of $\mathrm{Fe}$ (III)

\begin{tabular}{ccccc}
\hline SYSTEM $(\mathrm{Fe})$ & $\mathrm{n}$ & $1 / \mathrm{n}$ & $\mathrm{K}_{\mathrm{f}}(\mathrm{mg} / \mathrm{g})$ & $\mathrm{R}^{2}$ \\
\hline SMBC & 2.09 & 0.479 & 2.539 & 0.994 \\
UMBC & 0.58 & 1.729 & 13.131 & 0.873 \\
HMBC & 1.72 & 0.579 & 1.596 & 0.697 \\
\hline
\end{tabular}

$1 / \mathrm{n}$ is the adsorption intensity and $\mathrm{K}_{\mathrm{f}}$ is the adsorption capacity.

Table 5: Freundlich adsorption parameter for various adsorption systems of $\mathrm{Zn}$ (II)

\begin{tabular}{ccccc}
\hline SYSTEM $(\mathrm{Zn})$ & $\mathrm{n}$ & $1 / \mathrm{n}$ & $\mathrm{K}_{\mathrm{f}}(\mathrm{mg} / \mathrm{g})$ & $\mathrm{R}^{2}$ \\
\hline UMBC & 0.37 & 2.682 & 399.578 & 0.816 \\
SMBC & 1.34 & 0.746 & 1.023 & 0.860 \\
HMBC & 1.36 & 0.737 & 3.107 & 0.891 \\
\hline
\end{tabular}

$1 / \mathrm{n}$ is the adsorption intensity and $\mathrm{K}_{\mathrm{f}}$ is the adsorption capacity.

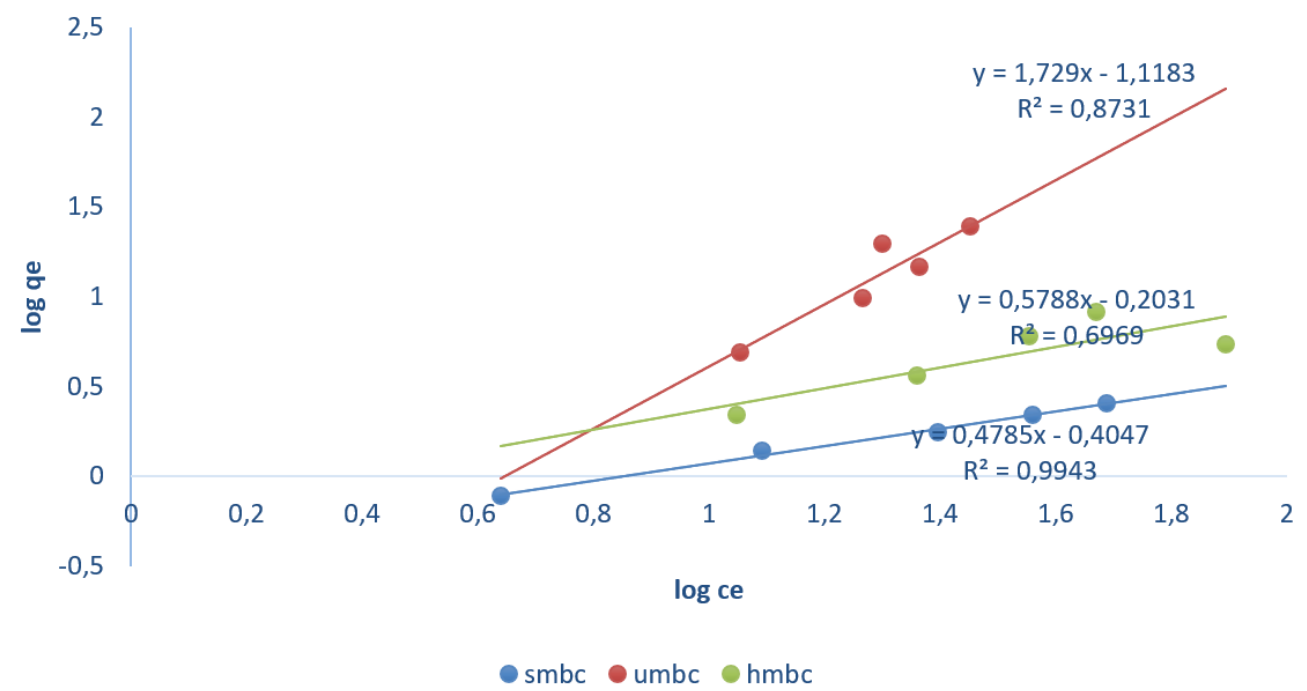

Figure 2c: Freundlich plot for UMBC//Fe, $\mathrm{HMBC} / / \mathrm{Fe}$, and $\mathrm{SMBC} / / \mathrm{Fe}$

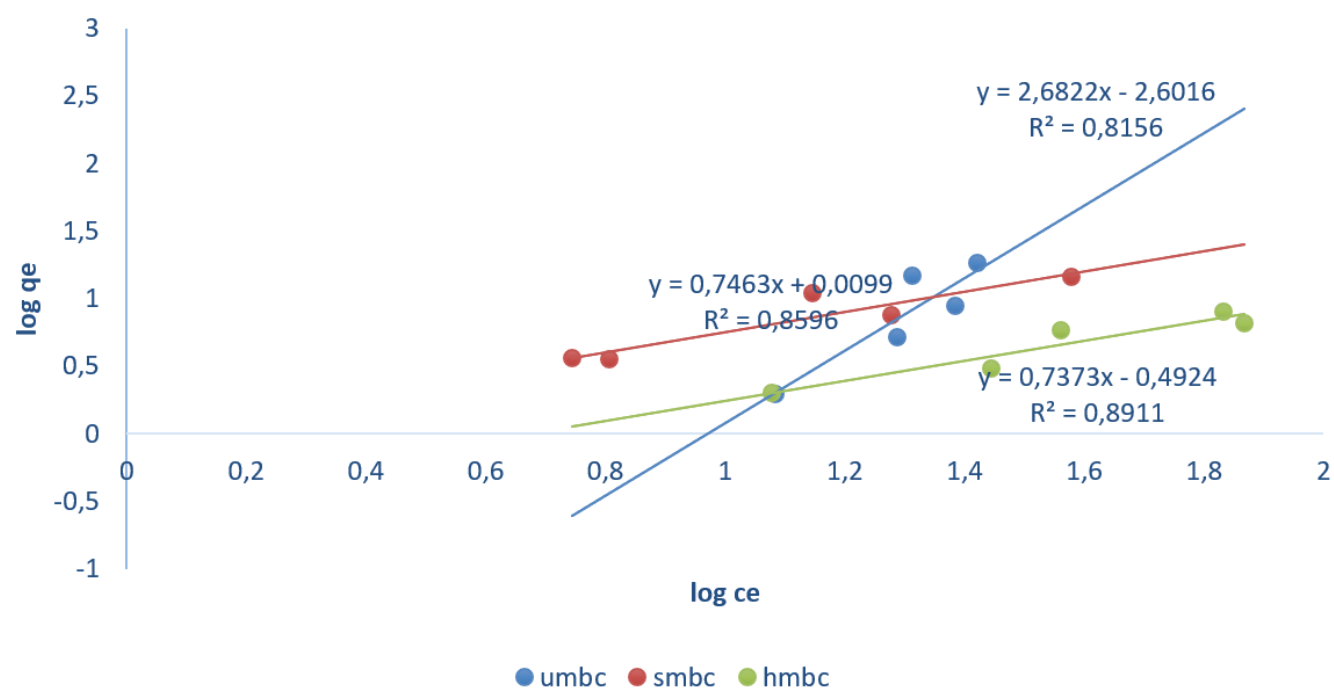

Figure 2d: Freundlich plot for $\mathrm{UMBC} / / \mathrm{Zn}, \mathrm{HMBC} / / \mathrm{Zn}$, and $\mathrm{SMBC} / / \mathrm{Zn}$ 


\section{Adsorption Kinetics and Mechanism}

The kinetic study explains how fast the rate of adsorption occurs. Adsorption type depends on the characterization of the adsorbents and the system conditions such as contact time, concentration, and temperature. Calculation of the adsorption rate constant is fundamental to evaluate the necessary qualities of a suitable adsorbent, such as a time required for adsorbent to remove a particular compound and efficacy of the adsorbents (30). Pseudo first order and pseudo-second-order kinetic models were employed to study the adsorption process. The validity of the kinetic models was tested by employing the correlation coefficient value $\left(R^{2}\right)$. The satisfactory model had excellent linearity of the plot (high $\mathrm{R}^{2}$ values). The pseudo-first-order plot for various adsorbents is shown in Figures 3a-b while the plot for pseudo-second-order for the various adsorbents is also shown in Figures 3c-d.

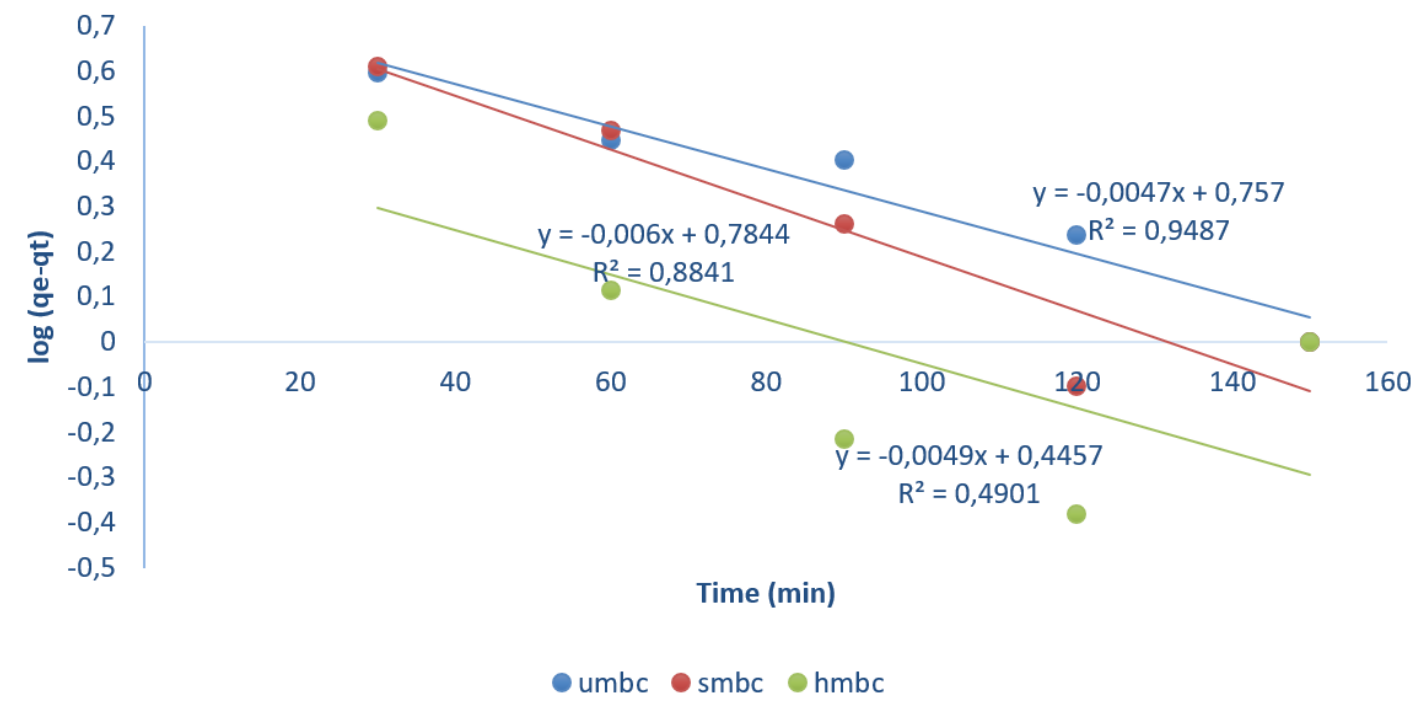

Figure 3a: Pseudo first order plot of UMBC//Fe, $\mathrm{HMBC} / / \mathrm{Fe}$ and $\mathrm{SMBC} / / \mathrm{Fe}$.

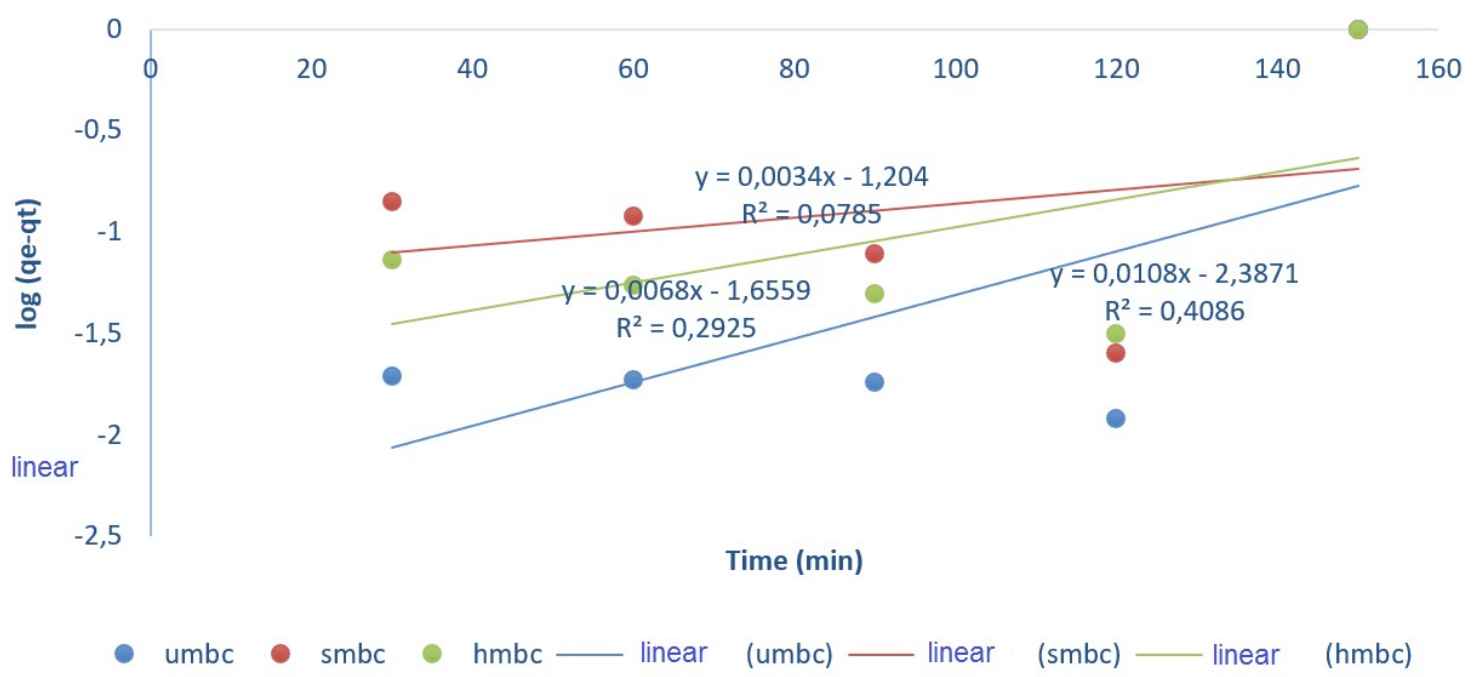

Figure 3b: Pseudo first-order plot of UMBC//Zn, $\mathrm{HMBC} / / \mathrm{Zn}$, and $\mathrm{SMBC} / / \mathrm{Zn}$.

The pseudo-first-order rate constant $\mathrm{k}_{1}$ amount of $\mathrm{Fe}$ (III) and $\mathrm{Zn}$ (II) adsorbed at equilibrium $\mathrm{q}_{\mathrm{e}}$ and correlation coefficient $\mathrm{R}^{2}$ are shown in Table
6-7. Proper fitting with high $\mathrm{R}^{2}$ was only observed for UMBC (0.948) for Fe(III), while the others showed poor agreement with kinetic 
models based on their $\mathrm{R}^{2}$ value. The parameters obtained from this model are summarised in Table 6-7. Therefore, the adsorption of Fe(III) and $\mathrm{Zn}$ (II) on different adsorbents of Bentonite

Table 6: Pseudo first order parameter for various adsorption systems of Fe(III)

\begin{tabular}{cccc}
\hline SYSTEM (Fe) & $\mathrm{k}_{1}$ & $\mathrm{q}_{\mathrm{e}}(\mathrm{mg} / \mathrm{g})$ & $\mathrm{R}^{2}$ \\
\hline UMBC & 0.010 & 5.71 & 0.948 \\
SMBC & 0.013 & 6.08 & 0.8841 \\
HMBC & 0.011 & 2.79 & 0.4901 \\
\hline
\end{tabular}

$\mathrm{K}_{1}$ is the pseudo-first-order rate constant; qe is the calculated equilibrium uptake capacities.

Table 7: Pseudo first order parameter for various adsorption systems of $\mathrm{Zn}$ (II)

\begin{tabular}{cccc}
\hline SYSTEM $(\mathrm{Zn})$ & $\mathrm{k}_{1}$ & $\mathrm{qe}_{\mathrm{e}}(\mathrm{mg} / \mathrm{g})$ & $\mathrm{R}^{2}$ \\
\hline UMBC & 0.024 & 243.83 & 0.408 \\
SMBC & 0.007 & 15.99 & 0.078 \\
HMBC & 0.015 & 45.27 & 0.292 \\
\hline
\end{tabular}

$\mathrm{K}_{1}$ is pseudo-first-order rate constant; qe is the calculated equilibrium uptake capacities.

The pseudo-second-order model showed favorable linearly with experimental data obtained for all the adsorbents. The plots are shown in Figures $\mathbf{3 c - d}$, respectively. Tables 8-9 tell that $R^{2}$ values of $0.972,0.995$, and 0.999 were obtained for UMBC//Fe, SMBC//Fe, and $\mathrm{HMBC} / / \mathrm{Fe}$, while the $\mathrm{R}^{2}$ values of 0.999 , 0.981 and 0.993 were obtained for UMBC,

SMBC and $\mathrm{HMBC} / / \mathrm{Zn}$ adsorbent respectively. These are higher than corresponding $\mathrm{R}^{2}$ values obtained in the pseudo-first-order model and described the kinetic data better. It informs that both the concentration of metal ions in solution and the number of available adsorption sites are critical in determining the rate/kinetics of the adsorption process.

Table 8: Pseudo second order parameter for various adsorption systems of Fe(III)

\begin{tabular}{cccc}
\hline SYSTEM (Fe) & $\mathrm{k}_{2}$ & $\mathrm{q}_{\mathrm{e}}(\mathrm{mg} / \mathrm{g})$ & $\mathrm{R}^{2}$ \\
\hline UMBC & 128.53 & 14.29 & 0.972 \\
SMBC & 327.55 & 17.99 & 0.995 \\
HMBC & 563.61 & 17.24 & 0.999 \\
\hline
\end{tabular}

$\mathrm{K}_{2}$ is the pseudo-second-order rate constant; qe is the calculated equilibrium uptake capacities.

Table 9: Pseudo second order parameter for various adsorption systems of $\mathrm{Zn}$ (II)

\begin{tabular}{cccc}
\hline SYSTEM (Zn) & $\mathrm{k}_{2}$ & $\mathrm{q}_{\mathrm{e}}(\mathrm{mg} / \mathrm{g})$ & $\mathrm{R}^{2}$ \\
\hline UMBC & 0.076 & 0.56 & 0.999 \\
SMBC & 0.005 & 0.53 & 0.981 \\
HMBC & 0.010 & 0.48 & 0.993 \\
\hline
\end{tabular}

$\mathrm{K}_{2}$ is pseudo second order rate constant; $\mathrm{q}_{\mathrm{e}}$ is the calculated equilibrium uptake capacities. 


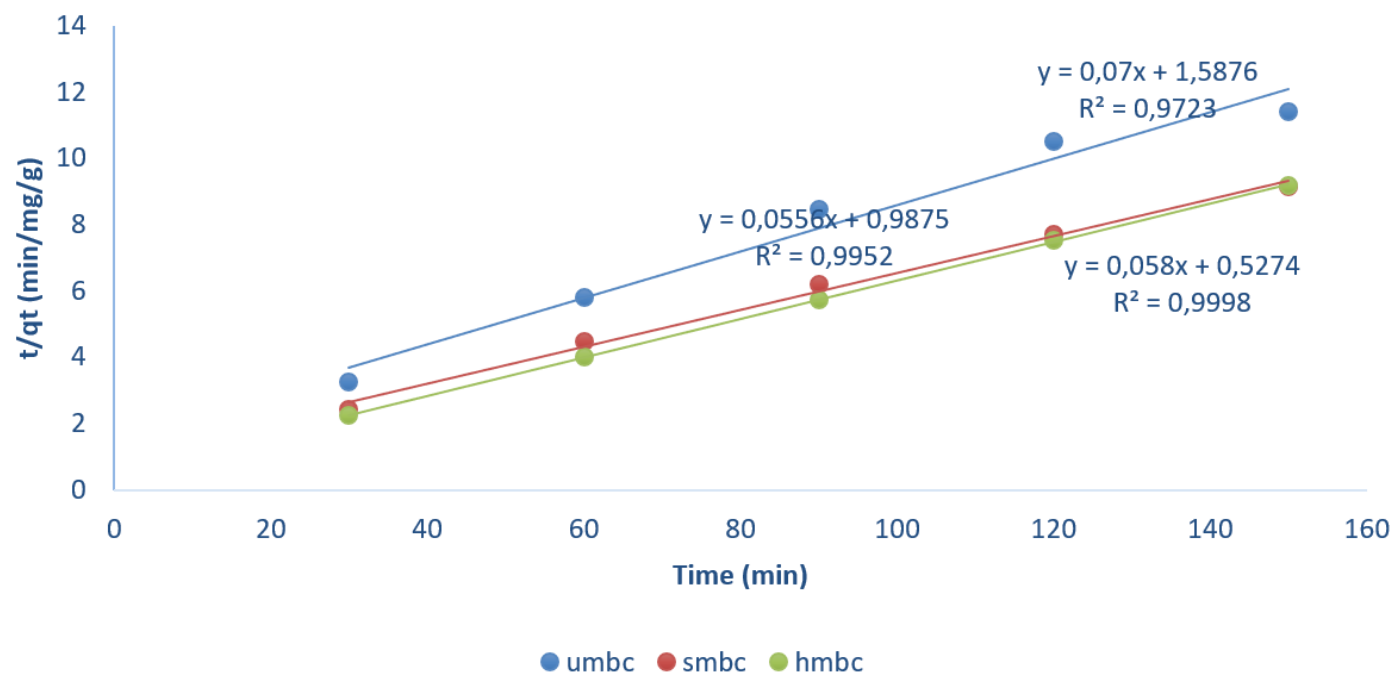

Figure 3c: Pseudo second order plot of $\mathrm{UMBC} / / \mathrm{Fe}, \mathrm{HMBC} / / \mathrm{Fe}$ and $\mathrm{SMBC} / / \mathrm{Fe}$.

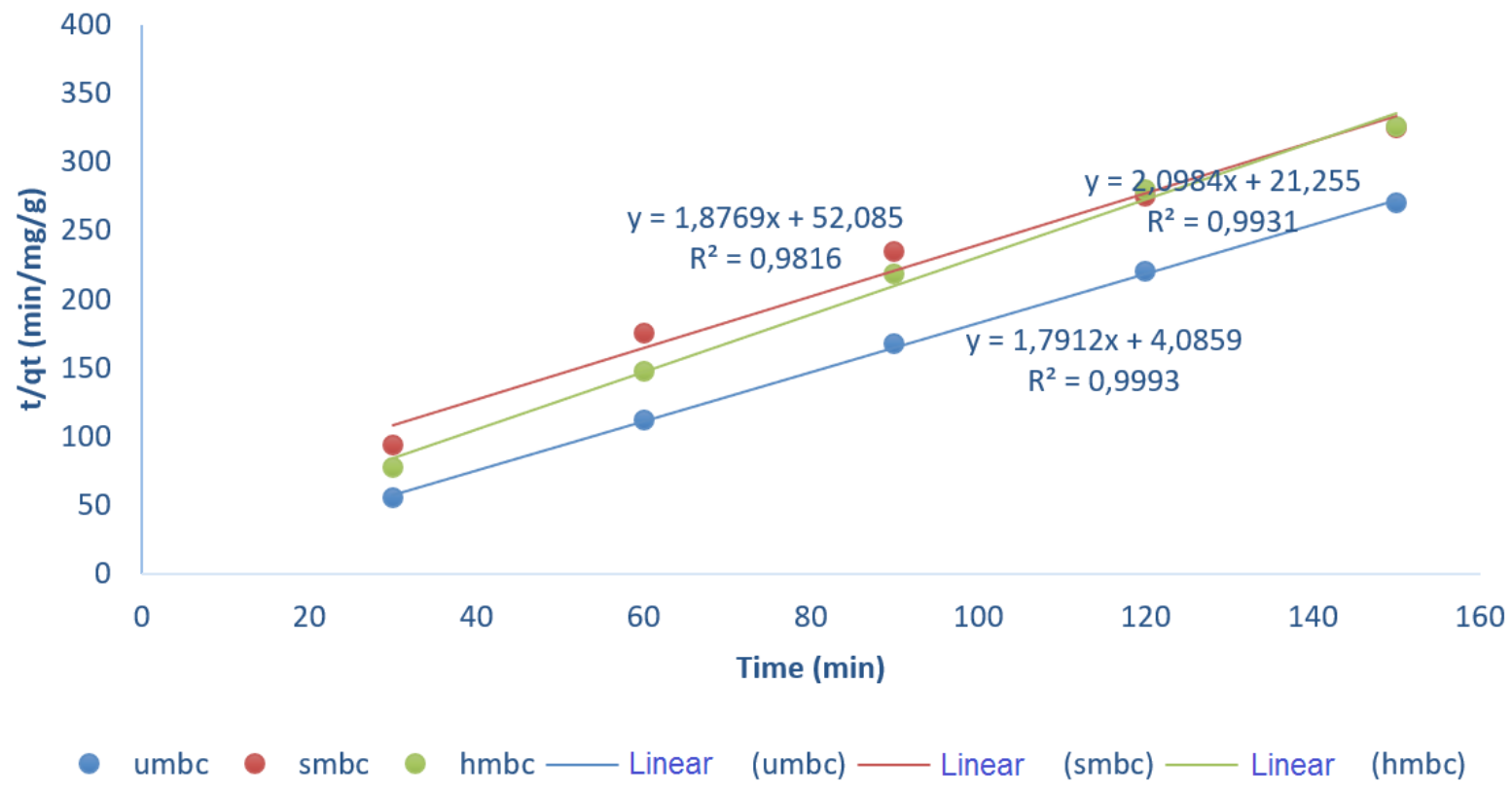

Figure 3d: Pseudo second order plot of UMBC//Zn, HMBC//Zn and SMBC//Zn

\section{Adsorption Thermodynamics}

Thermodynamic parameters can be useful in the evaluation of orientation of the adsorption process and which provide information regarding the mechanism of the process, structural changes, and energy due to molecular adsorption ion. All the thermodynamic parameters were determined using the system of equations shown in Eqn. 69. 


$$
\begin{aligned}
& \ln K=\frac{-\Delta H}{R T}+\frac{\Delta S}{R} \\
& \text { Eqn. 6, } \\
& \Delta G=-R T \ln K
\end{aligned}
$$$$
K=\frac{C_{o}-C_{e}}{C_{o}}
$$

Eqn. 8

$$
\ln \frac{K_{S 1}}{K_{S 2}}=\frac{-E_{a}}{R}\left(\frac{T_{2}-T_{1}}{T_{1} T_{2}}\right)
$$

temperature $T_{1}$ and $T_{2}$ respectively. The thermodynamic plot obtained from the equation for the various sorption systems studied are depicted in Figure 4, and the thermodynamic parameters obtained from these plots are summarised in Table $\mathbf{1 0}$.

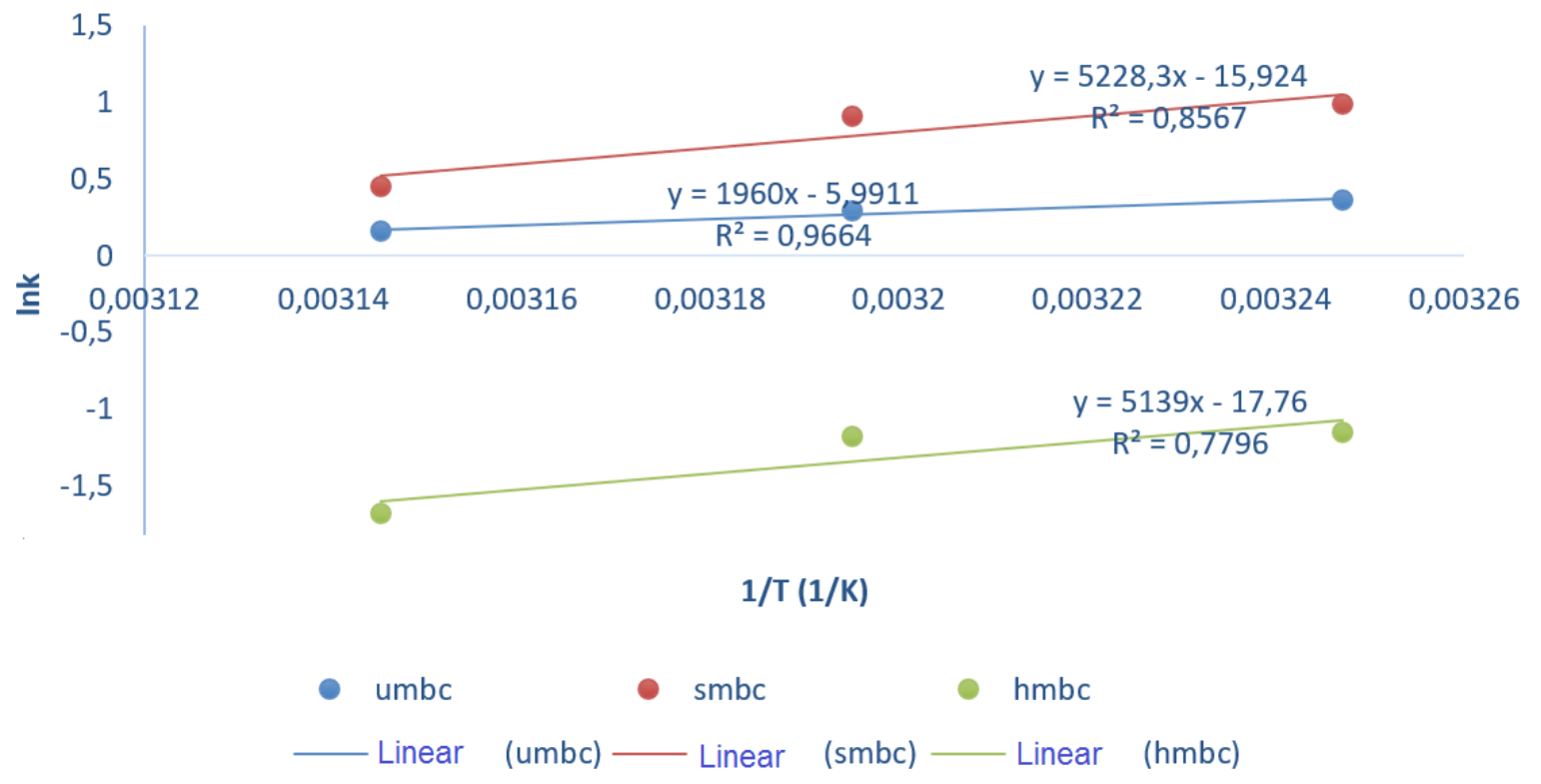

Figure 4: Thermodynamic plot of UMBC, HMBC and SMBC//Fe)

Table 10: Thermodynamic parameter for various adsorption systems of Fe(III)

\begin{tabular}{llllll}
\hline SYSTEM(Fe) & $\mathrm{T}(\mathrm{K})$ & $\begin{array}{l}\Delta \mathrm{G} \\
(\mathrm{KJ} / \mathrm{mol})\end{array}$ & $\begin{array}{l}\Delta \mathrm{H} \\
(\mathrm{KJ} / \mathrm{mol})\end{array}$ & $\begin{array}{l}\Delta \mathrm{S}(\mathrm{J} / \mathrm{mol} / \\
\mathrm{k})\end{array}$ & $\mathrm{R}^{2}$ \\
\hline Unmodified Bentonite Clay - type & 308 & -927.938 & -235.61 & -0.720 & 0.967 \\
(UMBC//Fe) & 313 & -761.218 & & & \\
& 318 & -428.398 & & & 0.858 \\
\hline Sulphuric acid modified Bentonite & 308 & -2536.61 & -628.79 & -1.914 & \\
Clay - type (SMBC//Fe) & 313 & -2358.68 & & & 0.781 \\
& 318 & -1202.51 & & 2.136 & \\
\hline Hydrochloric acid Modified & 308 & 2952.444 & 618.21 & & \\
Bentonite Clay - type (HMBC//Fe) & 313 & 3071.783 & & & \\
& 318 & 4442.479 & & & \\
\hline
\end{tabular}

The thermodynamic plot for the following adsorbents, namely, UMBC are plotted in Figure 4 gave $R^{2}$ value of 0.967 . The relatively high $R^{2}$ values can be attributed to the regular trends exhibited in their respective temperature profile diagram except for SMBC and HMBC with 0.858 and 0.781 respectively of $R^{2}$ value, which exhibited irregular trends in his temperature profile diagram. From Table 10, it was observed that all the $\Delta G$ values in the 
adsorption system are negative, which suggested that the process of adsorption is spontaneous over the range of temperature studied except for HMBC and HMKC in which $\triangle \mathrm{G}$ values are positive which indicate that the process of adsorption is not spontaneous. The $\Delta S$ values of $-0.720 \mathrm{~J} / \mathrm{mol} / \mathrm{k},-1.914 \mathrm{~J} / \mathrm{mol} / \mathrm{k}$ and $2.136 \mathrm{~J} / \mathrm{mol} / \mathrm{K}$ for UMBC, SMBC, and HMBC, respectively, which indicate that there is decrease and increase in randomness at the solid/solution interface during the adsorption. The $\Delta \mathrm{H}$ values were found to be -235.61 $\mathrm{KJ} / \mathrm{mol}$, and $-628.79 \mathrm{KJ} / \mathrm{mol}$, for UMBC, SMBC respectively suggest that the process is exothermic while $\Delta \mathrm{H}$ values were found to be $618.21 \mathrm{KJ} / \mathrm{mol}$ for HMBC which indicate that the process is endothermic.

\section{CONCLUSION}

From this study, acid-modified adsorbents were successfully prepared from Bentonite clays. Physicochemical properties of modified and unmodified adsorbents were observed to have significant differences in all parameters. Adsorbent dosage of $0.05 \mathrm{~g}$ and $\mathrm{pH}$ values of 8 were found to be the optimal value. The adsorption data in this study were best explained using the Langmuir isotherm model. Sulfuric acid-modified bentonite clay (SMBC) performs best among all the adsorbents. The kinetic data in this study was best explained by the pseudo-second-order kinetic model implying the physisorption process. The thermodynamic data show that HMBC showed that the process is endothermic and non-spontaneous. Negative of $\Delta S$ values indicated that there is a decrease in randomness except for HMBC at the solid/solution interface during the adsorption. Furthermore, it was observed that acid modification was helped to increase the sorption capacity of the clay to the heavy metals studied.

\section{DISCLOSURE STATEMENT}

Conflict of Interest: The authors declare that there are no conflicts of interest.

Compliance with Ethical Standards: This article does not contain any studies involving human or animal subjects.

\section{REFERENCES}

1. Adeniyi, A.G. and J.O. Ighalo, Biosorption of Pollutants by Plant Leaves: An Empirical Review. Journal of Environmental Chemical Engineering, 2019. 7(3): p. 103100 DOI: http://dx.doi.org/10.1016/j.jece.2019.103100.
2. Aziz, H.A., M.N. Adlan, and K.S. Ariffin, Heavy metals (Cd, Pb, Zn, Ni, Cu and $\mathrm{Cr}$ (III)) removal from water in Malaysia: Post treatment by high quality limestone. Bioresources Technology, 2008. 99(6): p. 1578-1583.

3. Landrigan, P.J., R. Fuller, N.J. Acosta, O. Adeyi, R. Arnold, A.B. Balde, R. Bertonllini, S. Bose-O'Reilly, J.I. Boufford, P.N. Breysse, and T. Chiles, The Lancet commission on pollution and health. The lancet, 2018. 391: p. 462-512.

4. Mohammed, A.-A. and Z. Al-Anber, Utilization of natural zeolite as ion-exchange and sorbent material in the removal of iron. Desalination, 2008. 255: p. 70-81.

5. Akpor, O.B., G.O. Ohiobor, and T.D. Olaolu, Heavy metal pollutants in wastewater effluents: sources, effects and remediation. Advances in Bioscience and Bioengineering, 2014. 2(4): p. 37-43.

6. Harvey, A.L., R. Edrada-Ebel, and R.J. Quinn, The re-emergence of natural products for drug discovery in the genomics era. . Natural reviews drug discovery, 2015. 14(2).

7. Ahmadi, M., H. Elmongy, T. Madrakian, and M. Abdel-Rehim, Nanomaterials as sorbents for sample preparation in bioanalysis: a review. Analytica Chimica Acta, 2017. 958: p. 1-21.

8. Nwosu, F.O., O.J. Ajala, R.M. Owoyemi, and G.B. Raheem, Preparation and characterization of adsorbents derived from Bentonite and kaolin clays. Applied Water Science, 2018. 8(195) DOI: http://doi.org/10.1007/s13201-018-08272.

9. Ajala, O.J., F.O. Nwosu, and R.K. Ahmed, Adsorption of Atrazine from aqueous solution using Unmodified and Modified Bentonite clays. Applied water science, 2018. 8(214): p. 1-11 DOI: http://dx.doi.org/10.1007/s13201-0180855-y.

10. Heydari, S., L. Zare, and H. Ghiassi, Plackett-Burman experimental design for the removal of diazinon pesticide from aqueous system by magnetic bentonite nanocomposites. Journal of Applied Research in Water and Wastewater, 2019. 6(1): p. 45-50.

11. De Souza, F.M., O.A.A. dos Santos, and M.G.A. Vieira, Adsorption of herbicide 2, 4-D from aqueous solution using organo-modified bentonite clay. Environmental Science and 
Pollution Research, 2019: p. 1-14.

12. Murrey, H.H., Applied Clay Mineralogy, Occurrences, Processing and Application of Kaolins, Bentonites, Palygorskite-Sepiolite, and Common Clays. Applied Clay Mineralogy. Vol. 2. 2007: Elsevier, .

13. Schütz, T., S. Dolinská, P. Hudec, A. Mockovčiaková, and I. Znamenáčková, Cadmium adsorption on manganese modified bentonite and bentonite-quartz sand blend. International Journal of Mineral Processing, 2016. 150: p. 32-38.

14. Tohdee, K. and L. Kaewsichan, Enhancement of adsorption efficiency of heavy metal $\mathrm{Cu}$ (II) and $\mathrm{Zn}$ (II) onto cationic surfactant modified bentonite. Journal of Environmental Chemical Engineering, 2018. 6(2): p. 2821-2828.

15. Yan, L., S. Li, H. Yu, R. Shan, B. Du, and T. Liu, Facile solvothermal synthesis of Fe304/bentonite for efficient removal of heavy metals from aqueous solution. Powder Technology, 2016. 301: p. 632-640.

16. Cantuaria, M.L., A.F. de Almeida Neto, E.S. Nascimento, and M.G. Vieira, Adsorption of silver from aqueous solution onto pre-treated bentonite clay: complete batch system evaluation. Journal of cleaner production, 2016. 112: p. $1112-1121$.

17. Alduaij, O.K., M.I. Attia, L. Khezami, and K.K. Taha, Removal of cobalt (II) from aqueous solution by local Saudi bentonite: Kinetic and equilibrium investigations. Macedonian Journal of Chemistry and Chemical Engineering, 2016. 35(1): p. 87-96.

18. Hanafiah, M.A., W.S. Ngah, S. Ibrahim, H. Zakaria, and W.A. Ilias, Kinetics and thermodynamic study of lead adsorption from aqueous solution onto rubber (Hevea brasiliensis) leaf powder. Journal of Applied Sciences, 2006. 6(13): p. 2762-2767.

19. Nwosu, F.O., O.J. Ajala, F.O. Okeola, S.A. Adebayo, O.K. Olanlokun, and O.A.A. Eletta, Adsorption of chlorotriazine herbicide onto unmodified and modified kaolinite: Equilibrium, kinetic and thermodynamic studies. Egyptian Journal of Aquatic Research, 2019 DOI: http://dx.doi.org/10.1016/j.ejar.2019.05.005.

20. Atsar, F.S., D.T. Kukwa, R.L. Tyohemba, E. A., and R.A. Wuana, Cleaning of heavy metals from Spent Lubrication Oil (SLO) by adsorption process using acid modified clay. International Journal of Chemical Science and Technology, 2013. 3(4): p. 71-75.

21. Ademoroti, M.A., Standard Methods for Water and Effluent Analysis. 1st ed, ed. E.M.a.M.S.o. Bioremediation. Vol. 2. 1996.

22. Olaniyi, I., O. Raphael, and J.O. Nwadiogbu, Effect of Industrial Effluent on the Surrrounding Environment. Scholars Research Library, 2012. 4(1): p. 406-413.

23. ASTM, Standard methods for acidity or alkalinity of water, in American Society Testing and materials. 1982: Philadelphia, USA.

24. APHA, Standard Methods for the Examination of Water and Wastewater. 2005, American Public Health Association: Washington, DC.

25. Ahmad, M. and W. Wan Zainal, Adsorption of malachite green onto cocoa pod husk-based activated carbon: Kinetics and equilibrium studies. Malaysian Cocoa Journal, 2010. 6: p. 41-47.

26. Baysal, Z., E. Cinar, Y. Buluk, H. Alkan, and M. Dogru, Equilibrium and thermodynamic studies of Biosorption of $\mathrm{Pb}$ (II) onto Candida albicans biomass. Journal of hazardous material, 2009. 161: p. $62-67$.

27. Onyeji, L.I. and A.A. Aboje, Removal of Heavy Metals from Dye Effluent using Activated Carbon Produced from Coconut Shell. International Journal of Engineering Science and Technology, 2011. 3(12): p. 8240-8243.

28. Ostroski, I.C., M.A.S.D. Barros, E.A. Silvab, J.H. Dantas, P.A. Arroyo, and O.C.M. Lima, A comparative study for the ion exchange of $\mathrm{Fe}$ (III) and $\mathrm{Zn}$ (II) on zeolite NaY. Journal of Hazardous Material, 2009. 161: p. 1404-1412.

29. Ozer, A. and H.B. Pirincci, Physical Adsorption of $\mathrm{Cd}$ (II) ions on sulphuric acid treated Wheat brain. Journal of Hazard and Material, 2006. 137: p. 849 - 855.

30. Ajayi, O., Kinetics and Thermodynamics of biosorption of copper, cadium and lead using water hyacinth and rice husk. 2013, University of Ilorin: Ilorin, Nigeria. 
Abdullahi AA et al. JOTCSA. 2020; 7(3); 727-744.

RESEARCH ARTICLE 